\title{
Data Gaps in Natural Resource Management: Sniffing for Leaks Along the Information Pipeline
}

\author{
HOLLY DOREMUS"
}

Despite wide recognition that natural resource management decisions are heavily dependent on the supply of scientific information, little attention has been paid to the processes by which that information is supplied. This paper lays out the key steps of the information supply pipeline, which include exploration, extraction, refining, blending, distribution, and consumption. Leaks in the pipeline can occur at any of these steps, interrupting the supply of information to decision makers. Because information supply is contextual and complex, no universal fix can address all information shortfalls. Nonetheless, several general recommendations emerge. First, decision makers must recognize the limits of scientific information, both in terms of the degree of precision and certainty attainable, and in terms of the need for other inputs into decisions. Second, priorities should be more consciously set, both on the broadest level across multiple resource demands and for specific problems. Third, freewheeling, creative exploratory research needs to be better encouraged. That will require more than increased funding; the training and cultures of both managers and researchers also need to be addressed. Fourth, the production of available information must keep up with theoretical advances. Targeted funding, incentives for information production, and institutions with an information production mission are all needed to ensure that extraction keeps pace. Fifth, collaboration needs to extend across traditional disciplinary, political, and institutional boundaries. Sixth, once information is produced, it needs to be archived in locations and formats that make it both accessible to and useful for future researchers and managers. Focusing on the information supply pipeline helps move discussion beyond the simplistic dichotomy of precaution versus certainty to the ways we can improve the information base for decisions and the value of those improvements.

* Professor of Law, University of California-Davis. An early draft of this paper was presented at a conference on "Missing Information: Environmental Data Gaps in Conservation and Chemical Regulation" at the Indiana University School of Law-Bloomington. Thanks to John Applegate and Robert Fischman for organizing the conference and inviting me to participate. In addition to Professors Applegate and Fischman, I am indebted to Adell Amos, Gordon Anthon, Kenneth Bamberger, William Buzbee, Joel Dobris, Mary Elliott, Christopher Elmendorf, Daniel Farber, Robert Glicksman, Dale Goble, James Griesemer, Albert Lin, Samuel Luoma, Paul Locke, Roberta Mann, Vicky Meretsky, Dennis Murphy, Hari Osofsky, David Parkhurst, J.B. Ruhl, Jennifer Sass, Rena Steinzor, Robert Tsai, Wendy Wagner, Mary Wood, Teresa Woods, Rosie Woodroffe, Matthew Zinn, and participants at a Georgetown University Law Center Environmental Law Workshop and a University of Oregon School of Law Faculty Workshop for sharing thoughts and suggestions on this topic. Obviously, all remaining errors and shortcomings are mine alone. Megan Jennings, Boalt Hall '07, and Jack McKenna, UC Davis '07, provided outstanding research assistance. Deans Rex Perschbacher (UC-Davis) and Christopher Edley (Boalt Hall) provided financial support for this project. 


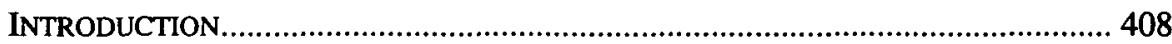

I. THE SCIENTIFIC INFORMATION SUPPLY PIPELINE .................................... 414

A. Useful Analogy: Fuel Supply from Crude Oil to Gasoline ................ 414

B. The Information Supply Pipeline: From Data to Decisions .............. 417

II. REPAIRS AND PREVENTIVE MAINTENANCE............................................. 443

A. Recognize the Limits of Scientific Information ................................. 444

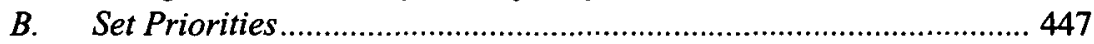

C. Encourage Management-Relevant Exploration ............................ 452

D. Make Sure Extraction Keeps Pace .............................................. 456

E. Break Down Disciplinary and Institutional Barriers....................... 459

F. Archive Information in Accessible Places and Useable Forms ........ 461

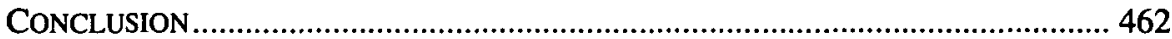

\section{INTRODUCTION}

It is widely recognized that information is a limiting factor for environmental and natural resource policy. ${ }^{1}$ Indeed, pervasive uncertainty in a variety of dimensions is regularly cited as a defining characteristic of environmental problems. ${ }^{2}$ The regulatory system is, as John Applegate has said, "ravenous" for information. ${ }^{3}$ That hunger is particularly acute in the context of natural resource regulation, ${ }^{4}$ where it appears to be increasing on an exponential scale that frustrates managers and observers. ${ }^{5}$

1. Professor Daniel Esty has drawn up a taxonomy of information needs, detailing the many points in the environmental decision-making process at which information is needed. Daniel C. Esty, Environmental Protection in the Information Age, 79 N.Y.U. L. REv. 115, 13139 (2004).

2. See, e.g., George H. Stankey, Roger N. Clark \& Bernard T. Bormann, Adaptive MANAGEMENT OF NATURAL RESOURCES: THEORY, CONCEPTS, AND MANAGEMENT INSTITUTIONS, USDA Forest SERVICE, PaCific NorthWEST RESEARCh STATION GEN. TECHNICAL REP. PNWGTR-654, at 1 (2005) [hereinafter Forest SERV., ADAPTIVE MANAGEMENT]; ROBERT v. Percival, Christopher H. Schroeder, Alan S. Miller \& James P. Leape, EnVIronmental Regulation: LAW, SCIENCE, AND POLICY 6 (2003); Daniel A. Farber, Uncertainty as a Basis for Standing, 33 HofSTRA L. REv. 1123, 1126-27 (2005); Paul C. Stern, Deliberative Methods for Understanding Environmental Systems, 55 BIOSCIENCE 976, 977 (2005); RICHARD J. LAZARUS, THE Making OF ENVIRONMENTAL LaW 16-21 (2004); John S. Applegate, The Taming of the Precautionary Principle, 27 WM. \& MARY ENVTL. L. \& PoL'y ReV. 13, 18 (2002); Holly Doremus, Constitutive Law and Environmental Policy, 22 STAN. ENVTL. L.J. 295, 319-21 (2003); Alyson C. Flournoy, Building an Environmental Ethic from the Ground Up, 37 U.C. DAvis L. REv. 53, 65 (2003); Alyson C. Flournoy, Legislating Inaction: Asking the Wrong Questions in Protective Environmental Decisionmaking, 15 HARV. ENVTL. L. REV. 327, 327 n.1 (1991) (listing additional sources); Bradley C. Karkkainen, Information as Environmental Regulation: TRI and Performance Benchmarking, Precusor to a New Paradigm?, 89 GEo. L.J. 257, 270-280 (2001); A. Dan Tarlock, Is There a There There in Environmental Law?, $19 \mathrm{~J}$. LAND USE \& ENVTL. L. 213, 238-39 (2004).

3. John S. Applegate, The Government Role in Scientific Research: Who Should Bridge the Data Gap in Chemical Regulation?, in RESCUING SCIENCE FROM POLITICS: REGULATION AND THE Distortion of SCIENTIFIC RESEARCh 255, 262 (Wendy Wagner \& Rena Steinzor eds., 2006).

4. For purposes of this Article, I intend the term "natural resource regulation" to cover management by federal, state, or local officials of government-owned resources as well as 
Demands come from multiple directions. First, regulators are choosing or being required to implement information-intensive approaches, such as broad-scale ecosystem management, temporally flexible adaptive management, or ecosystem service protection, which promise to improve conservation outcomes. ${ }^{6}$ The need to anticipate and respond to environmental change makes natural resource management intrinsically more information intensive than pollution control, where the health effects that are of primary concern are not constantly changing. In addition, natural resource decisions present opportunities for the incorporation of new information because they are frequently iterative, with the same or similar choices arising periodically. For example, although the decision to place a series of dams in the mainstem Columbia River was made decades ago, decisions about how to operate those dams must be made every year.

Second, political actors have an understandable tendency to tell regulators to balance on the knife-edge of accommodating conflicting societal interests in conservation and exploitation of resources. For example, the Endangered Species Act ("ESA") requires that permits be issued for the taking of listed species incidental to otherwise lawful activities if that taking will not jeopardize the continued existence of the species. ${ }^{7}$ In other words, there is a threshold of harm to the species which cannot be crossed, but development and resource extraction are to be allowed until that threshold is reached. ${ }^{8}$

government regulation of activities on private lands that affect public or quasi-public resources. Although I do not deal directly here with the management of private lands by conservationminded owners, I believe the informational challenges in that context are in many ways similar to those discussed here.

5. See, e.g., Mark Shaffer, Laura Hood Watchman, William J. Snape III \& Ingrid K. Latchis, Population Viability Analysis and Conservation Policy, in PopUlation VIaBILITY ANALYSIS 123, (Steven R. Beissinger \& Dale R. McCullough eds., 2002) ("The demand for answers is outstripping the supply of information on which to base them."); Richard B. Norgaard \& Paul Baer, Collectively Seeing Complex Systems: The Nature of the Problem, 55 BIOSCIENCE 953, 956 (2005) ("Economic interests now argue for business as usual until scientists can tell us everything with certainty ....").

6. See Forest SERV., ADAPTIVE MANAGEMENT, supra note 2, at 1-3; NAT'LOCEANIC AND ATMOSPHERIC ADMIN., U.S. DEPT. OF COMMERCE, NEW PRIORITIES FOR THE 21ST CENTURY: NOAA STRATEGIC PLAN, FY 2005-2010, at 4 (2004), available at http://www.ppi.noaa.gov/pdfs/Strategic_Plans/NOAA_Strategic_Plan.pdf; FISH \& WILDLIFE SERV., U.S. DEPT. OF THE INTERIOR \& NAT'L MARINE FisherIES SERV., NAT'L OCEANIC \& Atmospheric admin., U.S. Dept. OF Commerce, Habitat Conservation Planning and InCIDENTAL TAKe PERMIT Processing HandBooK 3-24 to 3-25 (1996); Robert L. Fischman \& Vicky J. Meretsky, Endangered Species Information: Access and Control, 41 WASHBURN L.J. 90 (2001); Oliver A. Houck, On the Law of Biodiversity and Ecosystem Management, 81 MinN. L. REv. 869 (1997); Robert B. Keiter, Beyond the Boundary Line: Constructing a Law of Ecosystem Management, 65 U. CoLO. L. Rev. 293, 314-16 (1994); Catherine M. Rigg, Orchestrating Ecosystem Management: Challenges and Lessons from Sequoia National Forest, 15 CONSERVATION BIOLOGY 78 (2001); John M. Volkman \& Willis E. McConnaha, Through a Glass, Darkly: Columbia River Salmon, the Endangered Species Act, and Adaptive Management, 23 ENVTL. L. 1249, 1258-61 (1993).

7. 16 U.S.C. $\$ 1539$ (a)(2)(B)(iv) (2000).

8. The Magnuson Fishery Conservation and Management Act sets up a similar dynamic; it requires that fishery management plans "prevent overfishing while achieving ... the optimum yield from each fishery ..." 16 U.S.C. $\$ 1851(\mathrm{a})(1)$ (2000). The Bush Administration's 
Resource users have grown increasingly vocal in their demands that the government demonstrate in advance that restrictions on resource use or destruction will be effective in achieving their stated conservation purpose. ${ }^{9}$ Under the rubric of "sound science," regulatory skeptics insist that high evidentiary standards are needed to, in the words of Justice Scalia, "avoid needless economic dislocation produced by agency officials zealously but unintelligently pursuing their environmental objectives." 10

A response to the extraordinary information intensity of natural resource management might be to seek policy approaches that impose lower information demands. That strategy has enjoyed some success in the pollution control context, where some of the least tractable scientific issues can be finessed by substituting technology-based requirements for harm-based targets. " It has only limited application in the natural resource context, however, because the fundamental problem is often competition for limited resources. At a given level of irrigation withdrawals from a river, fish will suffer less harm if diversion structures are screened to exclude them. But if withdrawals cause the river flow to fall below some minimum level, fish will die regardless of the technology applied at diversion points.

Another way to reduce information demands is to adopt a precautionary or "coarsefilter" approach, setting aside resources likely to be necessary for conservation without requiring a detailed showing of their importance. ${ }^{12}$ In today's political climate, these

roadless rule for the national forests provides a more nuanced example. The Clinton Administration had issued a rule essentially prohibiting timber harvest or road development in currently roadless portions of the national forest system, accepting the loss of some extractive use in order to ensure preservation of the ecological and aesthetic values of roadless areas. The Bush Administration rejected that approach. It adopted a baseline rule treating roadless areas like the rest of the system, but allowing states to petition for application of a more protective test. States applying for roadless area protection are required to describe in detail the lands for which they seek protection, the basis for protection, and impacts of protection on private property and reducing fire risks. 36 C.F.R. \& 294.14 (2007). Given that the lands in question are federal lands, requiring that state officials provide detailed information about them sets a high procedural bar. See Robert L. Glicksman, Traveling in Opposite Directions: Roadless Area Management Under the Clinton and Bush Administrations, 34 ENVTL. L. 1143 (2004) (detailing descriptions of the Clinton and Bush Administrations' very different policies regarding roadless areas).

9. In the Klamath Basin water conflicts, for example, irrigators attacked the decisions that cut off irrigation deliveries in 2001 on the grounds that the available evidence did not support regulators' claims that higher river flows and lake levels would benefit endangered and threatened fish. Holly Doremus \& A. Dan Tarlock, Fish, Farms, and the Clash of Cultures in the Klamath Basin, 30 EcoLogy L.Q. 279, 320-21 (2003).

10. Bennett v. Spear, 520 U.S. 154, 177 (1997). See also Holly Doremus, Science Plays Defense: Natural Resource Management in the Bush Administration, 32 ECOLOGY L.Q. 249, 261-63 (2005).

11. See, e.g., Howard Latin, Ideal Versus Real Regulatory Efficiency: Implementation of Uniform Standards and "Fine-Tuning" Regulatory Reforms, 37 STAN. L. REV. 1267 (1985); Sidney A. Shapiro \& Thomas O. McGarity, Not So Paradoxical: The Rationale for TechnologyBased Regulation, 1991 DukE L.J. 729; Wendy E. Wagner, The Triumph of Technology-Based Standards, 2000 U. ILL. L. Rev. 83, 96.

12. A precautionary approach intentionally transfers the information burden to those seeking to change the status quo. An example would be a general prohibition on new diversions from any stream containing an endangered fish unless the applicant could establish that the diversion would not harm the fish. A coarse filter strategy uses rough approximations or best 
types of strategies are not likely to close the information gap in natural resource management. The precautionary principle typically provides a justification for maintaining the status quo until we have enough information to persuade us that risks to human health or the environment are low enough to be worth taking. ${ }^{13}$ That may well be a desirable approach for deciding whether new chemicals or products made possible by novel technologies should be allowed on the market. ${ }^{14}$ It is a poor fit, though, for the many natural resource problems where the status quo already incorporates a high level of environmental modification and considerable risk to the resource. ${ }^{15}$ Precaution may justify the decision not to build the next dam, given uncertainty about the effects on troubled salmon runs. But appeals to precaution are not likely to lower the demand for information when the question is whether existing dams can continue to provide inexpensive power or irrigation water. By the same token, coarse-filter strategies will be a difficult political sell if society is divided on the relative values of conservation and extraction. A society that wants to have its cake and eat it too will not relish the potential for unnecessary conservation measures inherent in coarse-filter approaches. ${ }^{16}$

The bottom line, then, is that natural resource management decisions will inevitably remain highly information intensive for the foreseeable future. Yet little systematic work has been done to understand the pathways through which scientific information makes its way into these decisions. Certainly there has been some important scholarship related to information needs. Recognizing information as a limiting factor in environmental decisions, scholars have long focused considerable attention on strategies for decision making in the face of uncertainty. ${ }^{17}$ Others have highlighted the

guesses to reduce the information burden needed to justify management steps. The Clinton Administration's rule prohibiting construction of new roads in roadless areas on national lands was a coarse-filter strategy. See supra note 8.

13. See, e.g., Cass R. Sunstein, Laws Of Fear: Beyond The Precautionary Principle 13-15 (2005); Applegate, supra note 3; David A. Dana, A Behavioral Economic Defense of the Precautionary Principle, 97 Nw. U. L. REV. 1315 (2003); Robert V. Percival, Who's Afraid of the Precautionary Principle?, 23 PACE ENVTL. L. ReV. 21 (2005-06); Cass R. Sunstein, Irreversible and Catastrophic: Global Warming, Terrorism, and Other Problems, 23 PACE ENVTL. L. Rev. 3 (2005-06); Jonathan B. Wiener, Whose Precaution After All? A Comment on the Comparison and Evolution of Risk Regulatory Systems, 13 DUKE J. COMP. \& INT'L L. (SPECIAL ISSUE) 207 (2003).

14. See, e.g., Mary Jane Angelo, Embracing Uncertainty, Complexity, and Change: An Eco-pragmatic Reinvention of a First-Generation Environmental Law, 33 ECOLOGY L.Q. 105 (2006); John S. Applegate, The Prometheus Principle: Using the Precautionary Principle to Harmonize the Regulation of Genetically Modified Organisms, 9 IND. J. GLOBAL LEGAL STUD. 207 (2001); Rebecca Bratspies, The Illusion of Care: Regulation, Uncertainty, and Genetically Modified Food Crops, 10 N.Y.U. ENVTL. L.J. 297 (2002); Thomas O. McGarity, MTBE: A Precautionary Tale, 28 HARV. ENVTL. L. REv. 281 (2004).

15. But see Richard G. Hildreth, M. Casey Jarman \& Maggie Langlas, Roles for $a$ Precautionary Approach in U.S. Marine Resources Management, NAT. RESOURCES \& ENVT., Summer 2004, at 64 (supporting a precautionary approach to both new and existing uses of marine resources).

16. The Bush Administration's quick reversal of the Clinton-era national forest roadless rule suggests the political difficulties currently facing coarse-filter conservation. See supra note 8 .

17. See, e.g., Carl F. Cranor, Toward Understanding Aspects of the Precautionary Principle, 29 J. Medicine \& PHILOSOPHY 259 (2004); Marcia R. Gelpe \& A. Dan Tarlock, The 
importance of incentives for the production and disclosure of policy-relevant information, ${ }^{18}$ the role that information disclosure requirements or voluntary programs can play in the environmental policy portfolio, ${ }^{19}$ and the need for (and barriers to) acquisition and incorporation of new information over time.$^{20}$ In addition, there has been generalized discussion of the need for additional scientific information to support "second-generation" environmental policy decisions, ${ }^{21}$ as well as enthusiasm about the

Uses of Scientific Information in Environmental Decisionmaking, 48 S. CAL. L. REV. 371, 373 (1974); Douglas A. Kysar, Climate Change, Cultural Transformation, and Comprehensive Rationality, 31 B.C. ENVTL. AFF. L. REV. 555 (2004); Howard A. Latin, The Feasibility of Occupational Health Standards: An Essay on Legal Decisionmaking Under Uncertainty, 78 Nw. U. L. Rev. 583 (1983); Thomas O. McGarity, Politics by Other Means: Law, Science, and Policy in EPA's Implementation of the Food Quality Protection Act, 53 ADMIN. L. REv. 103 (2001); Richard B. Stewart, Environmental Regulatory Decision Making Under Uncertainty, 20 RES. IN L. \& ECON. 71 (2002); Cass R. Sunstein, Irreversible and Catastrophic, 91 CORNELL L. REV. 841 (2006).

18. See, e.g., Cary Coglianese, Richard Zeckhauser \& Edward Parson, Seeking Truth for Power: Informational Strategy and Regulatory Policymaking, 89 MINN. L. REv. 277 (2004); James E. Krier \& W. David Montgomery, Resource Allocation, Information Cost and the Form of Government Intervention, 13 NAT. RESOURCES J. 89 (1973); Mary L. Lyndon, Information Economics and Chemical Toxicity: Designing Laws to Produce and Use Data, 87 MiCH. L. REv. 1795 (1989); Stephen M. Johnson, Junking the "Junk Science" Law: Reforming the Information Quality Act, 58 ADMIN. L. REv. 37, 47-52 (2006); Wendy E. Wagner, Commons Ignorance: The Failure of Environmental Law to Produce Needed Information on Health and the Environment, 53 DUKE L.J. 1619 (2004).

19. See, e.g., David W. Case, Corporate Environmental Reporting as Informational Regulation: A Law and Economics Perspective, 76 U. CoLo. L. REV. 379 (2005); Karkkainen, supra note 2; Clifford Rechtschaffen, The Warning Game: Evaluating Warnings Under California's Proposition 65, 23 ECOLOGY L.Q. 303 (1996); Barton H. Thompson, Jr., Conservative Environmental Thought: The Bush Administration and Environmental Policy, 32 ECOLOGY L.Q. 307, 331-35 (2005); Michael P. Vandenbergh, From Smokestack to SUV: The Individual as Regulated Entity in the New Era of Environmental Law, 57 VAND. L. REV. 515, 529-33 (2004).

20. See, e.g., PANEL ON ADAPTIVE MGMT. FOR RES. STEWARDSHIP ET AL., NAT'L RESEARCH

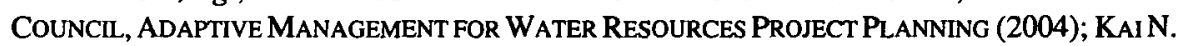
LEE, COMPASS AND GYROSCOPE: INTEGRATING SCIENCE AND POLITICS FOR THE ENVIRONMENT (1993); CARL WALTERS, ADAPTIVE MANAGEMENT OF RENEWABLE RESOURCES (Wayne M. Getz ed., 1986); Adaptive Environmental Assessment and Management (C.S. Holling ed., 1978); Fred Bosselman, A Dozen Biodiversity Puzzles, 12 N.Y.U. ENVTL. L.J. 364, 496-504 (2004); Donald T. Hornstein, Complexity Theory, Adaptation, and Administrative Law, 54 DUKE L.J. 913, 936-49 (2005); Bradley C. Karkkainen, Adaptive Ecosystem Management and Regulatory Penalty Defaults: Toward a Bounded Pragmatism, 87 MINN. L. REV. 943 (2003); Kai N. Lee \& Jody Lawrence, Adaptive Management: Learning from the Columbia River Basin Fish and Wildlife Program, 16 ENVTL. L. 431 (1986); J.B. Ruhl, Regulation By Adaptive Management: Is It Possible?, 7 MinN. J. L. SCI. \& TECH. 21 (2005); A. Dan Tarlock, A First Look at a Modern Legal Regime for a "Post-Modern" United States Army Corps of Engineers, 52 U. KAN. L. REv. 1285, 1309-24 (2004); John M. Volkman, How Do You Learn From a River? Managing Uncertainty in Species Conservation Policy, 74 WASH. L. REv. 719 (1999); Volkman et al., supra note 6.

21. Carol M. Rose, Environmental Law Grows Up (More or Less), and What Science Can Do to Help, 9 LEwIS \& ClARK L. REv. 273, 283-89 (2005) (noting the need for what she calls better "measurement" to support second-generation environmental policy measures). 
potential for new technologies to dramatically change the legal playing field by making new scientific information available or decreasing the costs of information acquisition, distribution, and analysis. ${ }^{22}$

As this body of work stands, however, it ignores a crucial aspect of the information gap problem: the complex processes by which scientific and technical information is produced, expressed, transmitted, and ultimately incorporated into decisions. ${ }^{23}$ While we will never have complete information, there may be ways to improve prioritization of information needs, and to make better use of existing information. Both require a clearer understanding of the workings of the information supply pipeline.

That pipeline, which ultimately provides the intellectual fuel for resource management decisions, can be usefully analogized to the process which supplies petroleum to fuel engines. Major steps include exploration, extraction, refining, blending, distribution, and finally consumption. Leaks in the pipeline, leading to information gaps, can occur at any point in the process. There certainly are problems of limited scientific effort, but there are also problems of limited communication, of information that is not well-matched to the management problem, and of institutions not capable of responding to information. "More information" is not always critical, or even helpful. ${ }^{24}$ Failure to get useful information to the right people can undermine decisions just as surely as failure to generate information. The same is true for failure to make effective use of available information. There is no a priori reason to suppose that any one type of failure is more frequent than another. ${ }^{25}$ Instead of reflexively calling for increased information production, therefore, we ought to take a broad look at the information supply chain, sniffing for leaks all along the way. ${ }^{26}$

22. See, e.g., Esty, supra note 1, at 155-74; Jamie A. Grodsky, Genetics and Environmental Law: Redefining Public Health, 93 CAL. L. REv. 171 (2005); Albert C. Lin, Beyond Tort: Compensating Victims of Environmental Toxic Injury, 78 S. CAL. L. Rev. 1439 (2005). But see David E. Adelman, The False Promise of the Genomics Revolution for Environmental Law, 29 HARV. ENVTL. L. REV. 117 (2005) (arguing that toxicogenomics is not likely to produce new information capable of radically reshaping the legal landscape).

23. In the legal literature, Professor Esty has come closest to recognizing the multi-stage nature of the information supply pipeline, acknowledging at least that the existence of information does not guarantee its availability to decision makers. Esty, supra note 1, at 207. Yet he only discusses the possibility that interested parties may withhold information. As discussed below, there are many other reasons why existing relevant information may be left out of the decision-making process. The social science literature is more attuned to the complexity of the problem, but has tended to address various aspects of it in isolation. I have not found a single source that broadly describes the information supply process and the many ways it can go awry.

24. Indeed, too much information can be as much a problem for decision makers as too little. Lee Clarke \& James F. Short, Jr., Social Organization and Risk: Some Current Controversies, 19 ANN. REV. OF Soc. 375, 380 (1993).

25. See David W. Cash, William C. Clark, Frank Alcock, Nancy M. Dickson, Noelle Eckley, David H. Guston, Jill Jäger \& Ronald B. Mitchell, Knowledge Systems for Sustainable Development, 100 PROCEEDINGS OF THE NAT'L ACAD. OF SCI. 8086, 8090 (2003) (calling for greater attention to the "demand side" of the information problem).

26. Leaks in hydrocarbon pipelines are traditionally detected by "sniffing" for escaping vapors. The technique is still in use, especially for buried or otherwise inaccessible pipelines, using machines and dogs rather than human noses. See U.S. ARMY CORPS OF ENG'RS, PUBLIC 
This Article lays the groundwork for a more sophisticated understanding of the scientific ${ }^{27}$ information gap problem in natural resource management. After setting out the oil pipeline analogy, it details the elements of the information supply pipeline, providing examples of leaks at each step. Drawing on that foundation, it then offers some concrete recommendations for repair and preventive maintenance in order to maximize the efficiency with which information travels through the line. My examples are drawn primarily from natural resource management, where the information problem is particularly acute. The conclusions are equally relevant, however, to pollution control, drug approval, or any other context in which policy decisions require scientific input.

\section{THE SCIENTIFIC INFORMATION SUPPL Y PIPELINE}

Scientific information is an input to regulatory decisions, just as petroleum is an input to transportation. Although the retail gas consumer is likely to be blissfully unaware of them, a number of steps are necessary prerequisites to the use of fuel to power an automobile. The same is true for use of information in natural resource regulation. In fact, the major steps correspond surprisingly well. ${ }^{28}$

\section{A. A Useful Analogy: Fuel Supply from Crude Oil to Gasoline}

For the car (assuming it's a conventional internal combustion model), the process of getting power to the wheels begins with oil exploration, which reveals the location of petroleum deposits. Next, the oil is extracted from the ground and transported via pipeline or tanker to a refinery. There, refining separates the crude oil into hydrocarbons of different chain lengths and breaks the longest chains into more valuable small molecules. The result is a series of hydrocarbon fractions corresponding to industrial solvents, gasoline, diesel fuel, heating oil, and lubricating oils. Chemical treatment of the fractions removes impurities. The gasoline fractions are then blended to create different grades of gasoline and mixed with additives to improve combustion

Works TeChNICAL BULl. No. 420-49-36, Leak Protection, at Appendix A (2001), available at

http://www.wbdg.org/ccb/ARMYCOE/PWTB/pwtb_420_49_36.pdf; W. KENT MUHLBAUER, PIPELINE RisK MaNaGEMENT MANUAL 7/160-7/161 (3d ed., 2004).

27. In this Article, I concentrate on scientific or technical information, by which I mean information, whether gathered by observation, experiment, or modeling, about the physical and biological world, because the scientific foundation for regulation has most frequently been the source of controversy. Other sorts of information, such as information about costs or about human behavior, can also be limiting for regulatory decisions. See, e.g., Esty, supra note 1, at 139 (displaying a chart of information needs for environmental decisions). Production and use of socioeconomic and behavioral information are plagued by many of the same difficulties that apply to the scientific information pipeline. See, e.g., J. Elizabeth Jackson, Robert G. Lee \& Paul Sommers, Monitoring the Community Impacts of the Northwest Forest Plan: An Alternative to Social Indicators, 17 SOC'Y \& NAT. RESOURCES 223 (2004) (noting, among other problems, limited data availability for socioeconomic evaluation of resource policy, and aggregation of that data at levels not appropriate to desired evaluation).

28. I am not claiming, of course, that the analogy is perfect, or that the consumption of information and oil are in all respects similar. Focusing simply on the number and type of steps necessary to go from raw material to use, though, I find a surprising and educational similarity. 
and decrease emissions. ${ }^{29}$ The fuel is distributed to gas stations by pipeline and truck, in some cases with additional blending of additives at the delivery stage. Finally, it is pumped by consumers into their vehicles. ${ }^{30}$

Bottlenecks can occur at any step in the process and for any number of reasons. Exploration may initially be limited by lack of knowledge about the system. At the dawn of the oil age, exploration consisted of drilling either randomly or near places where oil seeped to the surface. ${ }^{31}$ Gradually, as geologists learned more about the occurrence of oil below the surface, and just as importantly, accumulated sufficient successes to persuade oilmen of the usefulness of that knowledge, scientists and scientific tools came to play a more important role in exploration. ${ }^{32}$ Today, satellite photography, seismography, chemical studies, and computer imaging can be used in combination to assess the likelihood that oil-bearing rocks lie underlie the surface. These methods are expensive, though, and especially so in remote locations or offshore. As a result, they are generally employed only in areas already thought to be geologically (and presumably economically) promising. ${ }^{33}$ Moreover, even with these new technologies, the science of oil exploration remains highly inexact. The only way to be sure where oil lies is to drill for it. ${ }^{34}$ Even with modern knowledge and technology, only about one in five test wells proves productive, even in less than commercial quantities. ${ }^{35}$ Uncertainty extends beyond the presence or absence of oil to its quantity, as the range of estimates of recoverable oil underlying the Arctic National Wildlife Refuge attests. ${ }^{36}$

29. Additives have been used for many years to improve engine performance. Today, clean air regulations also require season- and location-specific additives. As of 2004, twelve different versions of "summer gas" were in use in different locations in the United States. Gov'T ACCOUNTABILITY OFFICE, MOTOR FUELS: UNDERSTANDING THE FACTORS THAT INFLUENCE THE RETAIL PRICE OF Gasoline, GAO-05-525SP, at 38-41 (2005) [hereinafter Gov'T ACCOUNTABILITY OFFICE], available at http://www.gao.gov/new.items/d05525sp.pdf.

30. See generally ROBERT O. ANDERSON, FUNDAMENTALS OF THE PETROLEUM INDUSTRY (1984); Gov'T ACCOUNTABILITY OFFICE, supra note 29, at 1-2; Chevron, What Is a Refinery?, http://www.chevron.com/products/learning_center/refinery/; ENERGY INFORMATION ADMINISTRATION, WHERE DOES MY GASOLINE COME From? (2006), http://www.eia.doe.gov/neic/brochure/gas06/gasoline06.pdf; U.S. DEPT. OF LABOR,

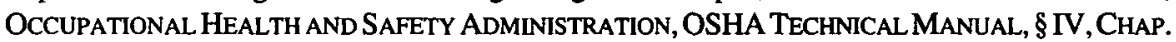
2 (1999), http://www.osha.gov/dts/osta/otm/otm_iv/otm_iv_2.html.

31. See ANDERSON, supra note 30, at 94; RoBert D. LANGenkAMP, Orl Business Fundamentals: Exploration, Leasing, Drilling, Production, Marketing 11 (1982). For thousands of years, people had put oil, tar, and asphalt that seeped to the earth's surface to a variety of uses, but the industrial era exponentially increased both the demand for petroleum products and the ability to extract them from the earth. See ANDERSON, supra note 30, at 2-11; Robert Sollen, AN OCEan Of OIL: A Century of Political Struggle OVer Petroleum off THE CALIFORNIA COAST 5-8 (1998).

32. See ANDERSON, supra note 30, at 94-96; Langenkamp, supra note 31, at 11-12.

33. ANDERSON, supra note 30 , at 100.

34. Id. at 101; Langenkamp, supra note 31 , at 15 .

35. ANDERSON, supra note 30 , at 96 .

36. The U.S. Geological Survey estimates that the coastal plain of the Arctic National Wildlife Refuge contains somewhere between 4.2 billion and 11.8 billion barrels of technically recoverable oil. U.S. Geological SuRvey, The OIl and Gas Resource Potential of THE arctic National Wildlife Refuge 1002 ARea, Alaska, Open File Report 98-34, at 10 
Once a promising site is located, the ability to extract oil is heavily dependent upon costs and the availability of technologies both for reaching deposits and for using them. It was not until after World War II that offshore operations became feasible with the development of, among other things, submersible drilling equipment and platforms capable of withstanding hurricanes. ${ }^{37}$ Even now, offshore operations remain confined to relatively shallow waters, despite the fact that a high proportion of oil-bearing rocks are thought to lie at great depths. ${ }^{38}$ Offshore operations are highly vulnerable to interruption by severe weather conditions. In 2005, hurricanes Katrina and Rita destroyed more than 100 offshore facilities and damaged more than 50 others. By June 2006, oil production in the Gulf of Mexico remained twenty-one percent lower than pre-storm levels. ${ }^{39}$ Onshore, oil sands, oil shale, and extra-heavy oil deposits are not yet heavily exploited because they are expensive to extract and require additional processing prior to use. ${ }^{40}$

Because crude oil has only limited uses, there is little point in extracting it unless it can be moved to a refinery for processing. Typically, that distribution is done by tanker ships, pipelines, or a combination of the two. Distribution requires capital-intensive physical and social infrastructure, including supertankers or large-diameter pipes extending long distances, ports capable of handling supertankers, and people with the specialized skills to operate ships and pipelines. Both ships and pipelines are vulnerable to the weather ${ }^{41}$ and to ordinary wear and tear, ${ }^{42}$ and pipelines are targets for vandalism. ${ }^{43}$ Distribution problems can force the shut-down of production

(1988), http://energy.cr.usgs.gov/OF98-34/ANWR1002.pdf. Another estimate places the maximum recoverable oil as low as 2.3 billion barrels. Francisco Rocha-Legoretta \& Ian Lerche, Oil and Gas Estimates for Arctic National Wildlife Refuge Area 1002, Alaska, 22 ENERGY EXPLORATION AND EXPLOITATION 161 (2004).

37. See Robert Gramling, OIL on the Edge: Offshore Development, Conflict, GRIDLOCK 37-55 (1996).

38. See ANDERSON, supra note 30, at 148.

39. Kris Axtman, Can Oil Companies Handle More Storms?, Christian SCI. Monitor, June 6, 2006, at 3. Because most offshore facilities in the Gulf shut down operations in anticipation of the storms, the initial impact was much higher, shutting down more than one quarter of U.S. domestic crude oil production. ENERGY INFO. ADMIN., U.S. DEPT. OF ENERGY, A PRIMER ON GASOLINE PRICES (2006), http://www.eia.doe.gov/bookshelf/brochures/ gasolinepricesprimer/printerversion.pdf.

40. David L. Greene, Janet L. Hopson \& Jia Li, Have We Run Out of Oil Yet? Oil Peaking Analysis from an Optimist's Perpsective, 34 ENERGY POL'Y 515, 516-18 (2006).

41. The 2005 Gulf of Mexico hurricanes did considerable damage to underwater pipelines that carry oil from off-shore rigs to on-shore refineries. See Tom Fowler, Despite the Havoc Caused by Recent Hurricanes, Oil Companies Continue to Work on Fields in the Gulf, HOUSTON CHRON., Nov. 8, 2005, at A1.

42. Corrosion produced a pinprick-sized hole in a pipeline leading to the Trans-Alaska Pipeline in the spring of 2006. Some 267,000 gallons of oil spilled from the leak over the course of several days before it was discovered. Felicity Barringer, Large Oil Spill in Alaska Went Undetected for Days, N.Y. TIMES, Mar. 15, 2006, at A 18.

43. In 2001, a drunken, down-on-his-luck Alaskan shot a hole in the pipeline with a rifle, causing a 286,000-gallon spill that cost $\$ 20$ million to clean up. Ben Spiess, He Never Had a Chance, AnChorage Dally News, Oct. 14, 2001, at A1; Pipeline Cleanup Near End, ANCHORAGE DaIl Y NeWS, Apr. 7, 2002, at B1. 
facilities. ${ }^{44}$ Like the pipelines or ships feeding them, refineries can fall victim to weather-related problems, as can distribution to retail outlets. ${ }^{45}$

Even if fuel makes it all the way through the process to a local gas station, it must still be compatible with the car pulling up to the pump. That is not always a given. When the catalytic converter was developed in the 1970s to decrease emission of unburned hydrocarbons, lead additives were still common in gasoline. Lead destroys catalytic converters. In the short run, before the government mandated for health reasons that lead additives be phased out of gasoline, ${ }^{46}$ owners of cars with catalytic converters had to search out stations with unleaded fuels. To prevent accidental use of the wrong fuel, the filler ports of cars with catalytic converters were required to be made sufficiently narrow so that they would not accept the wider nozzles used to deliver leaded fuels. ${ }^{47}$

In summary, as important as exploration for oil is, that alone will not make cars run. All of the elements of the supply pipeline need to work in concert for the ultimate goal of transportation to be achieved. Pumping more oil out of the ground will not get cars moving if there is a shortage of refineries or gas stations. Shortfalls in the fuel supply call for a look at the entire supply chain. The same is true for information shortfalls.

\section{B. The Information Supply Pipeline: From Data to Decisions}

Each of the steps in the oil supply chain has a counterpart in the information supply chain. Indeed, information supply is even more complex, because new information nearly always raises new questions, so that information production should be recursive. As a first approximation though, the oil supply chain analogy works reasonably well, drawing attention to the multitude of steps required for information supply. As with the oil industry, each step in the information supply chain is potentially vulnerable to problems. Furthermore, at any one step many different problems can occur. Diagnosing precisely where problems originate and what causes them can be difficult, but is an essential prelude to effective repairs.

\section{Exploration}

Scientific information prospecting requires noticing unanswered questions relevant to natural resource management, identifying techniques for answering those questions,

44. See Clifford Krauss \& Jeremy W. Peters, Biggest Oil Field in U.S. is Forced to Stop Pumping, N.Y. TIMES, Aug. 8, 2006, at A1 (noting that corrosion in a pipeline serving Prudhoe Bay oil field forced BP to temporarily halt production).

45. Shutdowns of both contributed to gasoline shortages in the wake of Hurricane Katrina. See ENERGY INFO. ADMIN., supra note 39.

46. See Frank Ackerman, Lisa Heinzerling, \& Rachel Massey, Applying Cost-Benefit to Past Decisions: Was Environmental Protection Ever a Good Idea?, 57 ADMIN. L. Rev. 155, 160-72 (2005) (discussing the rise and fall of leaded gasoline); C. Boyden Gray \& Andrew R. Varcoe, Octane, Clean Air, and Renewable Fuels: A Modest Step Toward Energy Independence, 10 TEX. REV. L. \& POL. 9, 15-26 (2005); Thomas O. McGarity, MTBE: A Precautionary Tale, 28 HARV. ENVTL. L. Rev. 281, 294-96 (2004).

47. See Regulation of Fuels and Fuel Additives, 38 Fed. Reg. 1254, 1256 (Jan. 10, 1973) (codified at 40 C.F.R. pt. 80). 
and finding locations or systems where those techniques might be put to good use. Risky, expensive, and uncertain as modern oil exploration is, searching for the scientific information needed to support natural resource management decisions is even more challenging. The geology of oil deposits is relatively well known at this point, so that at least prospectors have a good sense of what they hope to find. That may not be the case for scientific prospectors who deal with extraordinarily complex systems and often do not know in advance what parameters will be of management interest. For many, perhaps most, resource management decisions, we are still at the stage of not knowing what we do not know, and not knowing what techniques, or even what fields of study, are most likely to produce useful information. ${ }^{48}$

The limited funding available for environmental research is certainly one impediment to effective exploration. Federal support of management-relevant environmental research in government labs and in universities seems quite low by comparison to other fields, particularly medical research. According to the National Science Foundation ("NSF"), in fiscal year 2003 the federal government spent a total of $\$ 3.7$ billion to support research in "environmental sciences," a category that generally represents the study of the physical environment but also includes oceanography. ${ }^{49}$ Another $\$ 717$ million went to support research in "environmental biology," which includes ecology, evolutionary biology, population biology, and the like; just over $\$ 200$ million of that was in the form of grants for university-based research. ${ }^{50}$ By comparison, spending on the nonenvironmental biological sciences, which encompass medical and sub-organismal fields, was $\$ 18.6$ billion. $^{51}$

It is difficult to interpret these numbers for several reasons. The costs of different types of research can vary widely, and their societal benefits are difficult to compare. Moreover, the reported numbers likely both under- and over-report research with natural resource management significance. The reporting category of "environmental biology" excludes work in fields like anatomy or physiology, which might end up being highly relevant to resource management, while "environmental science" includes

48. As a prominent group of conservation scientists and practitioners has said, "sustaining species and ecosystems will require conserving at least some minimum amount-whether it is a number of individuals, a number of populations, or an area. The harsh reality is that for the vast majority of species, communities, or ecosystems, these minima are unknown. Lack of critical information on species and ecosystem distributions constrains conservation biologists' ability to test the underlying assumptions of conservation objective setting." Timothy $\mathrm{H}$. Tear, Peter Kareiva, Paul L. Angermeier, Patrick Comer, Brian Czech, Randy Kautz, Laura Landon, David Mehlman, Karen Murphy, Mary Ruckelshaus, J. Michael Scott \& George Wilhere, How Much Is Enough? The Recurrent Problem of Setting Measurable Objectives in Conservation, BIOSCIENCE, Oct. 2005, at 847. One could add that lack of knowledge about the basic biology and life cycles of species is at least as much of a problem as lack of knowledge about their distribution.

49. Div. OF SCI. RES. STUdies, NAT'L SCI. FOUND., FEDERAL FuNDS FOR RESEARCH AND DEVELOPMENT: FisCAL YeARS 2003-05, NSF 06-313, at 59 (2006), http://www.nsf.gov/statistics/nsf06313/nsf06313.pdf. The totals include grants for research at universities as well as direct government spending. For both environmental science and environmental biology, spending was roughly evenly divided between basic and applied research, as defined by NSF.

50. Id.

51. Id. at 146 . 
a considerable amount of NASA-funded research that may not be very relevant to natural resource conflicts. In addition, funding for environmental science and environmental biology research has risen at a faster rate than overall federal research spending over the past twenty years. ${ }^{52}$ With all those caveats, however, the low level of funding for ecology, population biology, and conservation biology-the biological fields likely to be most directly connected to resource management decisions-is striking. I am by no means the first to make this observation. EPA's Science Advisory Board has expressed dismay at the low level of that agency's commitment to ecological research. The Board has pointed out that not only does EPA's science budget continue to decline in real-dollar terms, but it also shows "a systematic bias against ecosystem research" ${ }^{23}$ and more generally against the kind of core basic research that can help identify and frame an early response to new challenges. ${ }^{54}$

Beyond the low levels of general support for exploratory science on natural systems, directed research efforts in support of specific management initiatives can fall victim to funding shortfalls. The 1994 Northwest Forest Plan included a commitment to experimental and adaptive management in ten specified areas, which are referred to as Adaptive Management Areas ("AMAs"). "Despite good intentions, the goal of devising and studying alternative management strategies essentially fizzled." 55 One reason was budgetary. When the plan was first implemented, the Forest Service provided funding to support adaptive management work. Within a few years, however, "much of this support disappeared," assigned to each AMA. ${ }^{57}$

Lack of funding, though, is only one barrier to exploration. Even if money is available, some questions can be very difficult to ask because of the inability to conduct controlled studies. As an example, despite years of intensive study, there is still little agreement about the relative importance of the impact of harvest, hatchery, logging, and dam operations on salmon in the Columbia River system because of the difficulty of isolating the effects of individual factors from each other and from changing ocean conditions. ${ }^{58}$

52. See id. at $299,301$.

53. U.S. EPA SCIENCE ADVISORY BOARD, SCIENCE AND RESEARCH BUDGETS FOR THE U.S. ENVIRONMENTAL PROTECTION AGENCY FOR FISCAL YEAR 2007, AN ADVISORY REPORT BY THE SCIENCE ADVISORY BOARD, EPA-SAB-ADV-06-003, at 2 (2006), http://www.epa.gov/science1/pdf/sab-adv-06-003.pdf. The Board noted that funding for ecological research declined by $\$ 30$ million from FY 2004 to 2007 , contrary to "the prevailing position that such research is critical for the Agency to better manage and track the benefits" of its environmental management activities. Id. at 11.

54. See id. at A-5; U.S. EPA SCIENCE ADVISORY BOARD, SCIENCE AND RESEARCH BUDGETS FOR THE U.S. ENVIRONMENTAL PROTECTION AGENCY FOR FisCAL YEAR 2006, AN ADVISORY REPORT BY THE EPA SCIENCE ADVISORY BOARD, EPA-SAB-ADV-05-002, at 4-5 (2005), http://www.epa.gov/science1/pdf/science_and_res_budgets_fy-2006_sab-adv-05-002.pdf.

55. Eric Stokstad, Learning to Adapt, SCI., July 29, 2005, at 688.

56. George H. Stankey, Roger N. Clark \& Bernard T. Bormann, Adaptive Management and the Northwest Forest Plan: Rhetoric and Reality, J. Forestry, Jan.-Feb. 2003, at 40, 43.

57. See id. at 44; Stokstad, supra note 55, at 690 ("When national forest budgets got tight, these experiments were axed or fell lower on priority lists.").

58. See Comm. on Prot. \& Mgmt. of Pac. Nw. Anadromous Salmonids, Nat'l Research Councl, UpSTREam: Salmon and SOCIETY IN THE PACIFIC NORTHWEST 39-74 
Exploratory work that is both feasible and relevant can also be delayed or prevented by subtle social, institutional, or legal barriers. Ironically, agencies' commitment to protecting the resources under their charge can be one of the most impenetrable barriers. It can make managers reluctant to conduct, or regulators reluctant to permit, controlled trials of management strategies assumed to be helpful. As Professor Donald Hornstein explains,

in determining the value of experimentation..., values will be discounted by the foregone benefits of applying the agency's existing regulations .... Especially when such values are high, for example when a species might become extinct or public health could worsen because of these foregone benefits, this discount rate will be high and the agency will perennially reach a rational cost-benefit calculation that it is not worth experimenting. ${ }^{59}$

Management of the Columbia River hydropower system illustrates the impacts of such implicit discounting. The Army Corps of Engineers transports juvenile salmon by barge around the mainstem Columbia River dams, keeping the fish out of the turbines without requiring the dams to spill water. In 1993, John Volkman and Willis McConnaha noted that managers recognized the paucity of data showing that barging increased survival, but were unwilling to run controlled tests because failing to transport a control group could, if barging was in fact helpful, pose unacceptable risks. ${ }^{60}$ Nearly fifteen years later, studies of mortality in barged versus in-river smolts are just beginning to appear in the peer-reviewed literature. ${ }^{61}$ It is still not known why barging does not increase survival to the extent that would be predicted on the basis of avoiding passage through the dams. Similarly, a study of implementation of the adaptive management provisions of the Northwest Forest Plan found that experimentation was inhibited by reflexive regulatory opposition to actions thought to pose a risk to endangered species. ${ }^{62}$ Managerial risk aversion is likely to be accentuated where management efforts are controversial and advocacy groups distrust each other and resource managers. ${ }^{63}$

(1996) (detailing the effects of changing ocean conditions and a variety of human activities on salmon).

59. Donald T. Hornstein, Complexity Theory, Adaptation, and Administrative Law, 54 DUKE L.J. 913, 947-48 (2005).

60. Volkman \& McConnaha, supra note 6, at 1260.

61. See, e.g., Carl B. Schreck, Thomas P. Stahl, Lawrence E. Davis, Daniel D. Roby \& Benjamin J. Clemens, Mortality Estimates of Juvenile Spring-Summer Chinook Salmon in the Lower Columbia River and Estuary 1992-1998: Evidence for Delayed Mortality?, 135 TRANSACTIONS OF THE AM. FiSHERIES SOC. 457 (2006); Tyler Wagner, James L. Congleton \& Douglas M. Marsh, Smolt-to-Adult Return Rates of Juvenile Chinook Salmon Transported Through the Snake-Columbia River Hydropower System, USA, in Relation to Densities of CoTransported Juvenile Steelhead, 68 FISHERIES RES. 259 (2004).

62. See Stankey et al., supra note 56 , at 43 . These researchers found that although managers typically attributed these inhibitions to inflexible laws, the real situation was more complex. The law allowed more flexibility than either managers or regulators appeared to understand or be willing to explore.

63. See Stokstad, supra note 55 , at 690 (noting that environmental groups fought what they saw as efforts to use AMAs "primarily to extract timber rather than to improve the ecosystems"); Douglas A. Kysar \& James Salzman, Environmental Tribalism, 87 MINN. L. REV. 1099 (2003) (discussing the tendency of opposing interests in resource disputes to demonize one 
The more high profile the problem, the more likely managers are to want to take some action in response, lest they be perceived as simply waiting for an endless series of studies. All too often, the result is that management actions, even those that arouse substantial opposition, may continue for decades without any evaluation of their effectiveness. Consider badger culling in Great Britain. Although it is still a relatively minor economic problem, bovine tuberculosis has proven difficult to control in Great Britain. Wild badgers provide a reservoir of tuberculosis (TB), and it is widely thought that they can transmit the disease to cattle. ${ }^{64}$ Destruction of badgers as a bovine TB control strategy began soon after they were first linked to the disease in 1973. Farmers and the government tried several different badger-culling strategies. Because environmentalists and animal welfare activists objected to any culling, by 1985 the predominant strategy was one of selective culling only in response to detection of TB in cattle. Until 1998, no attempt was made to rigorously evaluate the effectiveness of culling or to compare culling methods. ${ }^{65}$ Finally the government agreed to undertake a multi-year controlled trial, at a cost of $\$ 30$ million. ${ }^{66}$ Initial results were mixed and confusing. Looking at just the treated areas, there seemed to be a decrease in bovine TB with widespread proactive culling, but an increase over the controls with smallscale reactive culling in response to cattle infections. Looking beyond the treated areas though, provided an explanation. Ecological research had suggested that culling disrupts the social behavior of badgers, causing survivors to range more widely and perhaps putting them in contact with more cattle herds. Putting two and two together, scientists evaluated bovine TB incidence just outside the areas culled and found a significant increase. ${ }^{67}$ The controlled experiments were costly, but if heeded could have great value. They suggest that the reactive culling strategy on which managers had settled in their effort to accommodate all political stakeholders was probably the worst approach to the biological problem.

In addition to showing the value of actually testing the assumptions that underlie management choices, the badger case study shows the importance of involving creative, "academic-style" scientists who will continuously refine experiments. Had the badger researchers clung single-mindedly to the original protocol, which called only for collecting data from treated areas and matched controls, they would not have discovered the increased TB incidence in areas just outside the culling zones.

Academics are certainly not the only people who can or do think creatively about scientific problems. But it should not come as a surprise that in the badger case the researchers who did that kind of thinking were in fact academics serving on an independent advisory group to the government. ${ }^{68}$ The career paths leading to academic

another).

64. See, e.g., Christl A. Donnelly, Rosie Woodroofe, D.R. Cox, F. John Bourne, George Gettinby, Andrea M. Le Fevre, John P. McInerney \& W. Ivan Morrison, Impact of Localized Badger Culling on Tuberculosis Incidence in British Cattle, 426 NATURE 834 (2003); Ehsan Masood, Outcry as 'Scientific' Badger Cull is Launched to Target TB, 394 NATURE 821 (1998).

65. See Donnelly et al., supra note 64 , at 834 .

66. See Masood, supra note 64 , at 821 .

67. See Christl A. Donnelly, Rosie Woodroofe, D.R. Cox, F. John Boume, C.L. Cheeseman, Richard S. Clifton-Hadley, Gao Wei, George Gettinby, Peter Gilks, Helen Jenkins, W. Thomas Johnston, Andrea M. Le Fevre, John P. McInerney, \& W. Ivan Morrison, Positive and Negative Effects of Widespread Badger Culling on Tuberculosis in Cattle, 439 NATURE 843 (2006).

68. See Department for Environment, Food and Rural Affairs, Bovine TB: The Independent 
science tend to select those with an inclination toward and flair for broadly creative problem solving. Moreover, at least in theory, academics, unlike agency personnel, have the luxury of time and implicit institutional permission to pursue their wildest ideas. ${ }^{69}$ The late physicist Richard Feynman told the story of how his research career took off once he allowed himself to play with physics, puzzling out how a plate tossed in the air wobbled because that seemed interesting, rather than worrying about the need to do important work. ${ }^{70}$ Many modern academics might say that they experience the pressures to publish and get grants more strongly than comes through in Feynman's portrayal, ${ }^{11}$ but they nonetheless retain the autonomy in their working lives to pursue the obsessive curiosity that commonly motivates them. Academics are not likely to be interested in the minute details of specific management decisions, but they have the skills and opportunity to reduce the big gaps in understanding ecological systems that most plague those decisions. ${ }^{72}$

Unfortunately, it is not always easy to involve academic scientists deeply in the types of studies most needed to support natural resource management. The reward of academic prestige is still closely tied to publications in prestigious journals, which tend to be most interested in highly theoretical "pure" science studies. Furthermore, although academics are strongly buffered against adverse employment effects once they get tenure, before that they are advised to be cautious by following the generally accepted path in their discipline. Pursuing problem-oriented interdisciplinary studies is risky, because it is unlikely to produce as many prestigious publications as work in a single discipline. It may also pose problems when it comes time for tenure review, because reviewers from typical disciplinary backgrounds may not know how to evaluate cross-disciplinary work. ${ }^{73}$

Scientific Group on Cattle TB, http://www.defra.gov.uk/animalh/tb/isg/ (describing the Independent Scientific Group's charge and membership).

69. See Poul Degnbol, Henrik Gislason, Susan Hanna, Svein Jentoft, Jesper Raakjær Nielsen, Sten Sverdrup-Jensen, Douglas Clyde Wilson, Painting the Floor with a Hammer: Technical Fixes in Fisheries Management, 30 MARINE POL'Y 534, 538 (2006) (noting that "the workload of routine management does not allow time for strategic thinking or the luxury of exploring new solutions and tools").

70. See Richard P. Feynman as told to Ralph Leighton, SuREly You'Re Joking, Mr. Feynman! Adventures of a Curious Character. 143-74 (Edward Hutchings ed., Bantam Books trade ed. 1989) (1985).

71. These days it is hard to imagine a senior colleague telling a recent hire not to worry about whether he or she is meeting expectations beyond the classroom, as Feynman reports he was told. Id. at 173.

72. In the words of an experienced scientist-manager: "[O]ur best hope in preserving [the biota] lies in a better understanding of the biology of the organisms themselves, and this information is best derived through the university research community." Edwin P. Pister, Professional Obligations in the Conservation of Fishes, 55 ENVTL. BIOLOGY OF FISHES 13, 17 (1999) (alteration to original).

73. See, e.g., Lisa M. Campbell, Overcoming Obstacles to Interdisciplinary Research, 19 Conservation Biology 574, 574-75 (2005); Norgaard \& Baer, supra note 5, at 957-58; Andrew Sobel, Comments on Globalization, Interdisciplinary Research, Myopia and Parochialism, Government, Convergence, and Culture, 9 J. INT'L MGMT. 419, 420 (2003). It is easy to imagine a very different set of academic incentives where tenure candidates are judged, for example, on the contribution their research makes to solving societal problems. See Pister, supra note 72 , at 17 . Nevertheless, the academic system is remarkably resistant to attempts to implement that kind of change. 
Even after tenure, barriers remain. Young academics who pretend to fit the traditional mold of their discipline may find once they gain the freedom of tenure that "the mask has stuck to their face," 74 and they no longer want to do anything else. Of course, many academic scientists are strongly committed to conservation of the resources they study, and want to contribute to that cause. But they are busy people, with many professional demands on their time. Participation in scientific advisory groups, review committees and the like, especially if it does not produce publications or grants, has to be added on top of other professional demands. It can be a frustrating hobby, particularly if decision makers do not take the advice offered. On the other side, agency personnel, who may not be accustomed to the world of peer review, do not always appreciate the involvement of outside critics. To top it all off, scientists who jump into the policy realm are likely to find themselves in the middle of nasty conflicts, and even the target of personal attacks or attacks on their professional conduct. ${ }^{75}$ Even strong motivation to do meaningful work can evaporate in the face of such strong countervailing pressures.

\section{Extraction}

\section{i. The difference between exploration and extraction}

Extraction of scientific information is the collection of data by observation, experiment, or modeling once a promising lead has been developed. The distinction between exploration and extraction can be fuzzy, just as it is in the oil industry, where exploratory wells are drilled to see if commercial-scale extraction is feasible. Scientific exploration produces data, and data production frequently involves some creative exploratory steps as well. Scientists may keep adjusting their data collection protocols, and the questions they are asking, well into a study as they refine their understanding of the system.

While the boundary is surely fuzzy, distinguishing exploration from extraction highlights an important difference between two types of data collection. One is academic-style science, driven by the search for improved conceptual understanding of a system and motivated by insatiable curiosity. It implies self-conscious comparison of the data with existing understanding of how a system works. The point of exploration is to challenge, refine, and extend that understanding. Exploration need not take place in academia, but it requires a mind-set that is far more common in universities than in regulatory agencies. ${ }^{76}$ Explorers must be open to new approaches, not bound by standardized rules or prescriptions. They must be free to follow their ideas, without too

74. My colleague Joel Dobris introduced me to this expression.

75. Thomas O. McGarity, Our Science is Sound Science and Their Science is Junk Science: Science-Based Strategies for Avoiding Accountability and Responsibility for Risk-Producing Products and Activities, 52 U. KAN. L. REv. 897, 917-19 (2004); see also Wendy E. Wagner, Importing Daubert to Administrative Agencies Through the Information Quality Act, 12 J.L. \& POL'Y 589, 611 (2004) (noting attacks on researcher whose studies showed harmful effects of atrazine).

76. A few government agencies, notably in the natural resources context the U.S. Geological Survey (USGS), also adopt this model. The USGS is not a regulatory agency; it may therefore become easier to structure it like an academic institution. 
many bureaucratic constraints. Management-style routine data collection is a very different thing, focused on monitoring the behavior of a system over time or in response to perturbation in order to achieve or set a management goal rather than primarily to advance understanding. ${ }^{77}$ It may produce data that motivate a new way of looking at the system, but it does not begin with that in mind. The knowledge-driven quest for improved understanding is properly categorized as part of the "exploration" step of the pipeline, while the issue-driven collection of information falls in the "extraction" category.

Extraction is more likely to be carried out by or under the direction of resource managers, but that is not the key distinction. Extraction provides data that, given current beliefs about how the system works, lead to management decisions. Exploration produces data that either confirm or refute current beliefs about the system. It is permitted, even expected from time to time, to upset the assumptions underlying management decisions. The marbled murrelet, a small seabird that nests in the Pacific coastal forest and feeds in ocean waters, provides a concrete example. Because the marbled murrelet is listed as threatened under the ESA, ${ }^{78}$ state and federal officials generally require that landowners within its range survey for the bird, using established protocols, before they harvest timber. ${ }^{79}$ The point of those surveys is not to determine the needs of the marbled murrelet, but to determine whether a proposed timber harvest will interfere with those needs, as they are currently understood by the regulatory authorities. By contrast, a very different type of study has recently called into question current thinking about threats to the murrelet. Researchers at U.C. Berkeley studied murrelet diets to see if fishing, not just logging, might be affecting the bird. Their data suggest that the proportion of low trophic level species, such as krill, in the murrelets' diet has significantly increased over the past century, while the proportion of fish from higher up the food chain, such as sardines or anchovies, has decreased. ${ }^{80}$ The authors attribute the change in diet to reduced availability of top-level prey as human beings have "fished down the food web." ${ }^{81}$ It seems that murrelets, like

77. The difference between these two different types of studies has been expressed in a variety of ways. A National Research Council committee has explained that one focuses on cataloging what is present in a study area, collecting occurrence, distribution data, and documenting changes over time, while the other focuses on understanding those trends in order to identify cause-and-effect relationships. National RESEARCH COUNCIL, COMMTTTEE to IMPROVE THE U.S. GEOLOGICAL SURVEY NATIONAL WATER QUALITY ASSESSMENT PROGRAM, OPPORTUNITIES TO IMPROVE THE U.S. GeOlOgical SuRVEY NATIONAL Water Quality AsSESSMENT PRogram 6 (2002).

78. See 50 C.F.R. 17.11(h) (2005); Endangered and Threatened Wildlife and Plants; Determination of Threatened Status for the Washington, Oregon, and California Population of the Marbled Murrelet, 57 Fed. Reg. 45,328 (Oct. 1, 1992) (codified at 50 C.F.R. pt. 17).

79. See Nw. Forest Res. Council v. Pilchuk Audubon Soc., 97 F.3d 1161, 1167-70 (9th Cir. 1996) (upholding use of the Pacific Seabird Group protocol); DianE Evans MaCK ET AL., Methods for SURVEYing Marbled MURRelets in Forests: A ReVised Protocol of LAND MaNAGEMENT AND ReSEARCH (Pacific Seabird Group Technical Publication Number 2, 2003), http://www.pacificseabirdgroup.org/publications/PSG_TechPub2_MAMU_ISP.pdf.

80. Benjamin H. Becker \& Steven R. Beissinger, Centennial Decline in the Trophic Level of an Endangered Seabird After Fisheries Decline, 20 CONSERVATION BIOLOGY 470 (2006).

81. Id. at 476-77; see also Daniel Pauly et al., Fishing Down Marine Food Webs, 282 SCIENCE 1383 (1998). 
many people, prefer to eat near the top of the food chain if possible. Prey at lower trophic levels provide a lower energy return for the effort needed to catch them, leading the authors to speculate that the overfishing-induced decline of marine predators may have reduced the murrelets' reproductive success and thereby contributed to its decline. ${ }^{82}$ This study obviously was not intended to evaluate the impacts of a specific logging proposal, or even a specific fishing proposal, on the murrelet. Instead, the authors sought to advance general understanding of the causes of murrelet decline. An incidental consequence of their study, however, is that (at least if the study is confirmed and extended) it may lead regulators to look to fishing as well as logging as activities that must be controlled in order to achieve murrelet recovery.

Exploratory studies are not necessarily divorced from specific management decisions. Studies that seek to evaluate the assumptions, particularly the hidden or unrecognized assumptions, of management can provide important new streams of information. An example comes from attempts to conserve the endangered island fox (Urocyon littoralis), a species endemic to the Channel Islands off the coast of California. The fox is threatened in part by predation by golden eagles, which have arrived on the islands recently, attracted by a population explosion of feral pigs. The pigs, in addition to feeding eagles, cause problems for native vegetation. Island managers, therefore, have sought to eradicate them. They have assumed that removing pigs would also benefit the fox, since the presence of pigs has been a major factor in the fox's decline. ${ }^{83}$ They have been more reluctant to pursue golden eagles, especially by lethal methods, because of the eagles' charisma and the legal complications. ${ }^{84} \mathrm{~A}$ computer modeling study, however, indicated that eradicating pigs without removing eagles could lead to the rapid extinction of the island fox as eagles turn from preying on pigs to preying on foxes. ${ }^{85}$

The bottom line is that exploratory and extractive studies are not fungible. Both are needed. The two may be most effectively carried out through different institutions, but the results of both must find their way into regulatory decisions in order for conservation to be effective.

\section{ii. A partial catalogue of extraction shortfalls}

The U.S. government collects and compiles reams of environmental data every year. ${ }^{86}$ A 1997 estimate places total federal funding for the collection of environmental

82. See Becker \& Beissinger, supra note 80 , at 477.

83. Channel Islands Nat'l Park, U.S. Dep't of the Interior, Santa Cruz ISLand Primary Restoration Plan: Final Environmental Impact Statement 5 (2002), http://www.nps.gov/chis/parkmgmt/santa-cruz-island-eis.htm.

84. Golden eagles are protected by the Bald and Golden Eagle Protection Act, 16 U.S.C. \& 668-668d (2000), and the Migratory Bird Treaty Act, 16 U.S.C. $\S \S 703-11$ (2000 \& Supp. 2005). They may only be killed or captured in accordance with rules established by the Department of Interior. See 16 U.S.C. § 668(a); 16 U.S.C. § 703.

85. Franck Courchamp, Rosie Woodroffe \& Gary Roemer, Removing Protected Populations to Save Endangered Species, 302 SCIENCE 1532 (2003).

86. For a partial listing of federal environmental data programs, see U.S. Gov'T ACCOUNTABILITY OFFICE, ENVIRONMENTAL INFORMATION: STATUS OF FEDERAL DATA PROGRAMS THAT SUPPORT ECOLOGICAL INDICATORS, GAO-05-376 (2005). 
data at more than $\$ 600$ million annually. ${ }^{87}$ Nonetheless, data gaps plague natural resource managers. In the course of preparing a major 2002 report on the state of the nation's ecosystems, the Heinz Center could find all the data needed to support national analysis for only 33 of 103 key indicators. ${ }^{88}$

The reasons for these gaps are not obscure. Extraction is not as risky as exploration, but it still consumes substantial resources without offering immediate payoffs. Not surprisingly, it often has more political enemies than friends. Wendy Wagner has described in detail the challenge of getting private parties to generate or disclose information in the hazardous materials context. ${ }^{89}$ Similar difficulties apply in the conservation context, particularly where resource management impacts privatelyowned lands. ${ }^{90}$

But there is another side to the natural resource information problem. State and federal governments would appear to be in a strong position to extract information relevant to resource management, because they control or at least have the authority to access large amounts of land, ${ }^{91}$ marine waters, navigable fresh waters, and the atmosphere. Nonetheless, governmental information extraction efforts have frequently been curtailed, often because of fears that the resulting data would be used to strengthen regulation.

Perhaps the best known example of this phenomenon is the short, unhappy life of the National Biological Survey (NBS). In 1993, with the stated goal of improving scientific support for proactive resource management efforts, Secretary of the Interior Bruce Babbitt established the NBS on the model of the highly regarded United States Geological Survey (USGS), consolidating the Department's biological research functions in a single entity organized on a more academic than bureaucratic model. ${ }^{92}$

87. Comm. on Env't \& Natural Res., Executive Office of the President, National ENVIRONMENTAL MONITORING AND RESEARCH WORKSHOP PROCEEDINGS (Feb. 25, 1997) as cited in THE H. JOHN HEINZ III CENTER FOR SCIENCE, ECONOMICS, AND THE ENVIRONMENT, THE STATE OF THE NATION'S ECOSYSTEMS: MEASURING THE LANDS, WATERS, AND LIVING RESOURCES OF THE UNITED STATES 3 (2002) [hereinafter STATE OF THE NATION's ECOSYSTEMS].

88. Id. at 18. Partial data were available for another twenty-five indicators. Id.

89. See Wagner, supra note 18.

90. See, e.g., Peter Kareiva et al., Nat'l CTR. For ECological ANAlysis and SyNTHESIS \& THE AMERICAN INST. OF BIOLOGICAL SCIENCES, USING SCIENCE IN HabitaT CONSERVATION PLANS, 14 (1999) (detailing scientific limitations of habitat conservation plans); Stephen Polasky \& Holly Doremus, When the Truth Hurts: Endangered Species Policy on Private Land with Incomplete Information, 35 J. ENVTL. Econ. \& MGMT. 22 (1998) (explaining how the law gives landowners strong control of some information about the resources on their land, and the lack of incentives to disclose that information to regulators); Matthew E. Rahn, Holly Doremus, \& James Diffendorfer, Species Coverage in Multispecies Habitat Conservation Plans: Where's the Science?, 56 BIOSCIENCE 613 (2006) (detailing how limited the information about even the presence or absence of covered species is in approved habitat conservation plans).

91. The United States owns roughly $30 \%$ of the nation's land. U.S. CENSUS BUREAU, Statistical AbSTRact OF THE UNITED States: 2006, at 22, tbl. 548 (125th ed.), http://www.census.gov/compendia/statab/2006/tables/06s0348.xls.

92. See National Biological Survey; Establishment of Organization, 58 Fed. Reg. 63,387 (Dec. 1, 1993); Karen A. Scanna, The National Biological Survey: A Step Along the Path to Ecosystem Conservation, 4 N.Y.U. ENVTL. L.J. 134 (1995); Richard Stone, Babbitt Shakes Up 
The scientific and resource management communities had mixed reactions to the new agency, with enthusiasm for the integration of fragmented efforts but concern about loss of ties to the direct needs of managers. The property rights community, and the Republican majority in Congress, were unified in strong opposition to the Survey, which they saw as a threat to development of private property. ${ }^{93}$ In order to survive at all, the new unit had to accept a lower profile as a division of the established USGS, make do with a greatly reduced budget, ramp down its ambitious plans for a comprehensive survey of the nation's biota, and also deal with the morale problems inherent in the dislocation of hundreds of scientists from one agency to another with a very different culture. ${ }^{94}$

The NBS debacle defeated efforts to institutionalize a commitment to information extraction. Even without a dedicated institutional home, information extraction efforts could in theory be robust. A litany of examples of failure to extract information that is both readily available and highly relevant to management, however, suggests that the systemic information gaps that motivated NBS advocates remain. Collection of baseline information is less than sexy under the best of conditions. When budgets are tight, and especially when data are politically inconvenient, information extraction efforts become easy targets. Here are just a few examples:

- The Climate Reference Network established by the National Oceanic \& Atmospheric Administration (NOAA) in 2001 to provide a high-quality long-term record of climatic conditions across the United States saw its funding eliminated by Congress in the fiscal year 2005 budget. At the same time, funding for a system of observatories whose measurements of atmospheric $\mathrm{CO}_{2}$ levels over the past 50 years provided one of the earliest indications of global warming was deeply slashed. ${ }^{95}$ The attack prompted this reaction from one climate scientist: "It's almost as if some people don't want to know how the climate is changing .... . Maybe they prefer uncertainty, so that they can avoid taking action. 96

- In 2002, shortly after it issued a major report revealing the extent of contamination of the nation's waterways with antibiotics, pharmaceuticals, and a variety of other household chemicals, ${ }^{97}$ the USGS's Toxic Substances Hydrology Program found itself targeted for elimination by the Bush administration. $^{98}$

Science at Interior, 261 SCIENCE 976 (1993).

93. Frederic H. Wagner, Whatever Happened to the National Biological Survey?, 49 BIOSCIENCE 219, 220 (1999); see also Stone, supra note 92, at 976.

94. See Colin Macilwain, US Geological Survey Picks Up the NBS Pieces, 382 NATURE 658, 658 (1996); Wagner, supra note 93; conversation with Samuel N. Luoma, Senior Research Scientist, USGS (Mar. 25, 2006).

95. Jeffrey Mervis, NOAA Loses Funding to Gather Long-Term Climate Data, 307 SCIENCE 188 (2005).

96. Id. at 188 (quoting Kevin Trenberth of the National Center for Atmospheric Research).

97. Dana W. Kolpin, Edward T. Furlong, Michael T. Meyer, E. Michael Thurman, Steven

D. Zaugg, Larry B. Barber, \& Herbert T. Buxton, Pharmaceuticals, Hormones, and Other Organic Wastewater Contaminants in U.S. Streams, 1999-2000: A National Reconnaissance, 36 ENVTL. SCI. \& TECH. 1202 (2002).

98. Greg Fuhs, U.S. Congress Seeks to Maintain USGS Water Science Funds, WATER 
- Although the Clean Water Act directs the states to report every two years to the EPA on the water quality of all navigable waters within their boundaries, ${ }^{99}$ water quality monitoring covers only a small proportion of the nation's waters. ${ }^{100}$ Surely not every mile of every stream needs to be directly tested, but the reports provide neither justification for sample selection nor reason to believe that the data produced provide any information about the miles not sampled. The problem, it seems, is that the law assumes that stream segments are not impaired unless data affirmatively show impairment. ${ }^{101}$ As a result, information can only tighten the regulatory noose, and economic interests have every incentive to oppose its gathering.

- The Fish Passage Center, which provides technical data about salmon movement downstream through the mainstem Columbia River dams, came under fire from Idaho Senator Larry Craig after environmental groups used some of its data in a lawsuit that resulted in a court order to increase the amount of water spilled over those dams. ${ }^{102}$ Craig managed to get a paragraph placed in the Conference Report for the Fiscal Year 2006 Energy and Water Development Appropriations Act ${ }^{103}$ forbidding further funding of the Fish Passage Center. ${ }^{104}$ As directed by the Report, the Bonneville Power Administration did cut off funding for the Center, but the Ninth Circuit has ordered support restored pending resolution of a lawsuit brought by environmental groups. ${ }^{105}$

ENV'T \& TECH., Oct. 1, 2002, at 29-30. Congress refused to go along with the administration's request to eliminate the program, but its budget has been essentially flat since at least 2000 , the earliest year for which budget data is available by program office at the USGS web site.

99. 33 U.S.C. $\$ 1315$ (b)(1) (2000) (emphasis added).

100. Less than $20 \%$ of river miles nationwide were assessed for the 2000 reporting cycle. EPA, NATIONAL WATER QUALITY INVENTORY: 2000 RePORT at ES-3 (Aug. 2002), http://www.epa.gov/305b/2000report/. For the 2002 reporting cycle, EPA has made available only the raw state reports; no national totals for the proportion of waters assessed (or for the proportion impaired) have been calculated. California reported in 2000 that it had assessed the status of less than $12 \%$ of its river miles. Id. at 85 . By 2002 , it had made a small measure of progress, with assessed river miles up to more than $15 \%$. http://iaspub.epa.gov/waters/w305b_report_v2.state?p_state=CA\#total_assessed_waters.

101. See 40 C.F.R. $\$ 130.2(j)$ (2006) (defining "water quality limited segment" as "[a]ny segment where it is known that water quality does not meet applicable water quality standards ...") (emphasis added).

102. Paul VanDevelder, The Tide May Be Turning for Salmon, L.A. Times, Feb. 4, 2007, at 3.

103. Energy and Water Development Appropriations Act for the Fiscal Year 2006, Pub. L. No. 109-103, 119 Stat. 2276 (2005); H.R. REP. No. 109-275, at 174 (2005) ("The Bonneville Power Administration may make no new obligations in support of the Fish Passage Center.").

104. Peter Sleeth, Groups Challenge Move to Cut Fish Study Funding, Oregonian (Portland), Jan. 24, 2006, at B5; Yudhijit Bhattacharjee ed., Random Samples: People, 310 SCIENCE 16131613 (2005).

105. Order, Nw. Envtl. Def. Ctr. v. Bonneville Power Admin., No. 06-70430 (Mar. 17, 2006), available at http://www.peaclaw.org/objects/FPC_Order.pdf. The lawsuit asserts that the Northwest Power Act requires continued funding of the Fish Passage Center. Petition for Review, Nw. Envtl. Def. Ctr. v. Bonneville Power Admin., No. 06-70430 (Jan. 20, 2006), 
One of the biggest challenges for extraction, given the realities of short-term budget and political cycles, is the maintenance of long-term data collection efforts. Because of lack of funding, for example, states and the federal government are ending support for river gauges which have been collecting data for decades. The continuous long-term records provided by these gauges have been invaluable in evaluating climate change and flood risks. ${ }^{106}$ The demand for this sort of long-term baseline information will only increase as more and more long-term management initiatives are undertaken. ${ }^{107}$ Difficult as it is to ensure that those initiatives remain in place for such long time frames, it is even tougher to maintain the fiscal and political discipline necessary to support long-term monitoring efforts. ${ }^{108}$

It is not just baseline data that are not being extracted. Monitoring and evaluation of the impacts of management actions fall short just as frequently. As Professor Hornstein points out, "federal administrative agencies have shown relatively little interest in systematic program evaluation as a general matter." 109 Monitoring drains scarce agency resources without providing the political benefits of action. It may even threaten to scuttle delicate political compromises if it highlights problems with existing management efforts. As a result, post-decision monitoring of management steps is the exception rather than the rule, and opportunities for learning are regularly squandered. Again, just a handful of examples should suffice to make the point: No federal agency has a systematic program for following up to see if the predictions made in National Environmental Policy Act (NEPA) documents turn out to be accurate. ${ }^{110}$ The U.S. Army Corps of Engineers has done little to monitor the effectiveness of wetlands mitigation efforts. ${ }^{111}$ The Fish and Wildlife Service undertook no analysis of the effectiveness of its costly condor reintroduction program for more than a decade. ${ }^{112}$

available at http://www.peaclaw.org/objects/BPA_final_petition.pdf.

106. John Schwartz, Experts See Peril in Reduced Monitoring of Nation's Streams and Rivers, N.Y. Times, Apr. 11, 2006, at F3.

107. Incidental take permits issued under the Endangered Species Act, to cite just one example, run as long as 100 years. In a quick scan of the U.S. Fish and Wildlife Service's online database of approved incidental take permits, I counted two of 100 years, four of ninety-nine years, and sixty-eight of fifty years duration. http://ecos.fws.gov/conserv_plans/servlet/ gov.doi.hcp.servlets.PlanReport.

108. See, e.g., Dominick A. DellaSala \& Jack E. Williams, Special Section: The Northwest Forest Plan: a Global Model of Forest Management in Contentious Times, 20 CONSERVATION Biology 274, 275 (2006) (noting that proper assessment of the Northwest Forest Plan will require periodic monitoring "for at least the next 100 years").

109. Donald T. Hornstein, Complexity Theory, Adaptation, and Administrative Law, 54 DUKE L.J. 913, 947 (2005).

110. See Bradley C. Karkkainen, Toward a Smarter NEPA: Monitoring and Managing Government's Environmental Performance, 102 CoLUM. L. REv. 903, 927 (2002) (noting that in most cases we never know the actual environmental impacts of actions evaluated under NEPA because neither federal agencies nor anyone else regularly conduct any follow-up analysis or monitoring).

111. See Nat'l Research Councll, Compensating for Wetland LOSSES UNDER the CleAN WATER ACT 3 (2001).

112. Fischman \& Meretsky, supra note 6, at 96. 


\section{Refining}

For the information pipeline, refining means turning raw data into useful information. Data are not the same as information or knowledge. ${ }^{113}$ Data are numbers generated by observation, measurement, or modeling. Information implies an understanding of the significance of those numbers, and knowledge and understanding of the underlying system itself. Neither of those follows automatically from data, although both can be derived from it. The key distinction is that information can improve management, but raw data typically cannot.

One common step in the transition from data to knowledge is boosting the signal-tonoise ratio by emphasizing the data that mean something and downplaying those that do not. Reviewing data to make sure they have been accurately measured and recorded seems like a trivial refining step, but, under pressure to meet performance expectations on limited budgets, it does not always happen. ${ }^{114}$ Beyond that, sorting data may be essential to accurate interpretation. For example, butterflies spend more time in flight on calm, warm days than when it is cold and windy. ${ }^{115}$ Ideally, therefore, butterfly population counts should be made during good weather conditions, but at a minimum, weather conditions during the survey should be recorded with the count numbers and taken into account in evaluating the significance of those numbers. Rather than being averaged with others, counts made under poor weather conditions may have to be ignored.

The appropriate geographic scale for data aggregation must also be determined. Averaging across too large an area can obscure important distinctions, but focusing on too small a sample can exaggerate meaningless differences. Exxon is currently wrangling with the U.S. and Alaska about this sort of data selection. The civil settlement following the Exxon Valdez oil spill required the company to pay $\$ 900$ million in restitution for damage to Prince William Sound. It also included a reopener clause, allowing the state and federal governments to seek up to an additional $\$ 100$ million for additional damages not anticipated at the time of the settlement. In June 2006, shortly before the reopener period was to expire, the governments submitted claims for $\$ 92$ million. ${ }^{116}$ Exxon points to hundreds of peer reviewed studies that, looking at the Sound as a whole, show a healthy recovery. But other studies, which

113. See generally Lee Clarke, Context Dependency and Risk Decision Making, in ORGanizations, UNCERTAINTIES, AND RISK 27 (James F. Short, Jr. \& Lee Clarke eds., 1992); Thomas D. Beamish, Accumulating Trouble: Complex Organization, a Culture of Silence, and a Secret Spill, 47 SOC. PROBS. 473, 479 (2000).

114. See, e.g., U.S. Gov't ACCOUNTABILITY OfFICE, Forest ServicE: BeTter DATA ARE NEEDED TO IDENTIFY AND PRIORITIZE REFORESTATION AND TIMBER STAND IMPROVEMENT NEEDS, GAO-05-374, at 16-17 (2005) (noting that in the reforestation program "data are not reviewed for accuracy and when errors are found they are not always corrected" because officials "emphasize addressing needs rather than accurately identifying and reporting them").

115. Thomas Reid assocs., San Bruno Mountain Habitat Conservation Plan, 1997 ACTIVITIES REPORT 6 (Jan. 1998).

116. Felicity Barringer, $\$ 92$ Million More Is Sought for Exxon Valdez Cleanup, N.Y. TiMES, June 2, 2006, at A14. 
focused on the portions of the Sound that were hardest hit by the spill, conclude that oil lingers and wildlife have not recovered. ${ }^{117}$

Statistical tests are another tool for sorting data to boost the signal-to-noise ratio. Statistics are used both to convert data gathered from multiple observations to a best guess at an actual property of the system, such as the size of a population of management concern, and to decide whether observations support inferences about the system, such as whether the population is shrinking over time. ${ }^{118}$ Statistical analysis always incorporates expert judgments, either explicitly, as in Bayesian analysis, or implicitly, as with the choice of statistical confidence levels in frequentist analysis. ${ }^{119}$

Closely related to statistical analysis are representations of uncertainty and determinations about how to express data. Rigidly applying frequentist statistical tests can lead to flat statements that a result is significant, implying that decision makers should give it great weight, or that it is not significant, implying that they should give it none. Both judgments can be misleading, obscuring the ultimate question of the weight to be assigned to differing data, ${ }^{120}$ a question best answered on a sliding scale rather than with a yes/no choice.

The format in which data are expressed as they are passed along to decision makers can also be important. In the fisheries context, Eagle and Thompson suggest that presenting regional fishery management councils with a range of potentially acceptable catch levels encourages the adoption of quotas at or above the top of the range presented, increasing the risk of overfishing. ${ }^{121}$ They suggest instead that the data should be expressed in terms of the probability that any particular quota will result in overfishing. $^{122}$

Refining is an essential aspect of the information supply pipeline. Raw data are simply not a useful basis for most decisions. Refining involves a great deal of judgment, however, and therefore introduces the possibility of hidden biases and systematic errors. As part of the process for making natural resource management or other policy decisions, the refining step bears close scrutiny in order to highlight the judgments made, who made them, and on what basis. ${ }^{123}$

117. Elizabeth Arnold, Valdez: The Damage Persists, 17 Years Later, National Public Radio, Weekend Edition (Apr. 15, 2006), available at http://www.npr.org/templates/story/ story.php?storyId=5344108.

118. David E. Adelman, Scientific Activism and Restraint: The Interplay of Statistics, Judgment, and Procedure in Environmental Law, 79 NOTRE DAMEL. REv. 497, 506-07 (2004). Professor Adelman's paper is the most complete and accessible explanation of the techniques and uses of statistics in the legal literature.

119. See id. at 563-75 (describing judgment in Bayesian analysis), 541-59 (describing judgment in frequentist analysis).

120. Id. at 559 .

121. Josh Eagle \& Barton H. Thompson, Jr., Answering Lord Perry's Question: Dissecting Regulatory Overfishing, 46 OCEAN \& COASTAL MGMT. 649, 671-72 (2003).

122. Id. at 672-73.

123. See generally Holly Doremus \& A. Dan Tarlock, Science, Judgment, and Controversy in Natural Resource Regulation, 26 Public LaND \& Resources L. Rev. 1 (2005); Holly Doremus, Using Science in a Political World: The Importance of Transparency in Natural Resource Regulation, in RESCUING SCIENCE FROM POLITICS (Wendy Wagner \& Rena Steinzor eds., Cambridge Univ. Press 2006). 


\section{Blending}

Blending is the combination of data or information from various sources. It is virtually unheard of for data collected at a single time in a single location by a single entity to supply by itself all the information relevant to a management decision. As Richard Norgaard and Paul Baer explain: "The modern human predicament can be described as the challenge of taking informed action ... based on the whole of knowledge, in a world in which knowledge, both practical and scientific, is highly fragmented and dispersed." 124 Typically, informed decision making requires the synthesis of disparate information streams. Three different sorts of blending are important to natural resource decisions.

The first is synthesis of similar data collected at different places or times. Longterm or large-scale trends can only be detected and understood if data are aggregated and evaluated together. Aggregation, though, is neither automatic nor simple. The production of natural resource data in the United States, like natural resource management, is highly decentralized. Information is produced by state governments, private entities, and a wide variety of federal agencies. Not surprisingly, these different entities, driven by different goals, tend to collect different data, and even to store it in different formats. It is difficult even to compile data for broader comparisons; there simply are not readily available databases either of conservation data or of research studies that have been conducted. ${ }^{125}$ It may be difficult for one agency to find out what data another has gathered. In the rare cases where data can be located and assembled, differences in methodology can still make comparisons difficult or impossible.

Information fragmentation also occurs within individual federal agencies. In the Forest Service, for example, data about reforestation needs are collected and compiled at hundreds of district offices under loose regional and national direction. ${ }^{126}$ The resulting data are sufficiently inconsistent that they "cannot be meaningfully aggregated at the national level." ${ }^{127}$ Even within individual offices, decisions made by different persons or at different times can fail to integrate information, increasing the likelihood that cumulative effects will be missed. ${ }^{128}$

The second type of blending involves analogizing or extrapolating from data collected under one set of circumstances to other circumstances. Under the right circumstances, data drawn from one situation can be combined with knowledge about another to draw reasonably robust conclusions about the second situation despite the absence of direct data. It is, needless to say, a tricky business. Both the need for and

124. Norgaard \& Baer, supra note 5, at 953.

125. Shaffer et al., supra note 5, at 137.

126. U.S. GOV'T ACCOUNTABILITY OFFICE, supra note 114, at 7-8.

127. Id. at 14 .

128. It does not help that permit applicants may be motivated to obscure, or at least not to highlight, similarities. For example, two environmental assessments prepared by the same consultant and submitted on the same day in support of incidental take permit applications for the Utah prairie dog in almost precisely the same place contain no mention of each other. Environmental Assessment for the Issuance of an Incidental Take Permit for the Utah Prairie Dog by the West Hills L.L.C. (June 16, 1995) (on file with author); Environmental Assessment for Issuance of an Incidental Take Permit for the Utah Prairie Dog by the Coleman Company, Inc. (June 16, 1995) (on file with author). 
the challenges of extrapolation are well known in the toxics regulation context, where regulators must estimate the impacts of low doses on human beings from data on high dose animal exposures. ${ }^{129}$ In the natural resource context, the analogous need is for extrapolation from one species or system to another. "Nearly nothing is known, quantitatively, about the population ecology of the vast majority of species."130 Potentially, careful study of a representative cross section of species could provide models for similar but less-studied species; at the moment, however, there is no established methodology for making this leap. ${ }^{131}$

The third important type of blending is the combination of data and interpretations from multiple disciplinary perspectives. ${ }^{132}$ Natural resource problems cannot be solved without some understanding of the way ecosystems function. That understanding inevitably requires "the insights of a variety of disciplinary experts." 133

Different disciplinary backgrounds not only allow people to address distinct facets of complex problems, they affect problem definitions and priorities. These differences provide a good part of the value of cross-disciplinary input, but also multiply its challenges. Environmental problems are "wicked," to use the terminology of Rittel and Webber, in the sense that they cannot be objectively defined. ${ }^{134}$ The nature of the problem, and therefore what counts as a solution, are in the eye of the beholder. ${ }^{135}$ Consider, for example, how many different answers there might be to the question of what would constitute a well-managed national forest, or how the waters of a river

129. See, e.g., David M. Driesen, Is Cost-Benefit Analysis Neutral?, 77 U. Colo. L. REv. 335, 340 (2006); Wendy E. Wagner, The Science Charade in Toxic Risk Regulation, 95 Colum. L. REv. 1613, 1625-27 (1995); Donald T. Hornstein, Reclaiming Environmental Law: A Normative Critique of Comparative Risk Analysis, 92 CoLUM. L. REv. 562, 571-73 \& n.43 (1992).

130. Shaffer et al., supra note 5, at 136.

131. See id. ("Whether or not [a cross section of species] could legitimately serve as models for other, unstudied species of similar life history ... may bear further consideration.").

132. Fine distinctions are sometimes drawn between inter-, multi-, cross-, and transdisciplinary approaches. See Svein Jentoft, Beyond Fisheries Management: The Phronetic Dimension, 30 MARINE POL'y 671, 675-76 (2006) (citing numerous useful sources). See generally Gabriele Bammer, Integration and Implementation Sciences: Building a New Specialization, 10(2) ECOLOGY \& SOC'Y 6 (2005) available at http://www.ecologyandsociety.org/vol 10/iss $2 /$ art6/. For purposes of this paper, the distinctions are not significant. The point is that no individual discipline can solve any important resource problem by itself. Connections of some sort must be made between disciplines.

133. Peter W. Cullen, Richard H. Norris, Vincent H. Resh, Trefor B. Reynoldson, David M. Rosenberg, \& Michael T. Barbour, Collaboration in Scientific Research: A Critical Need for Freshwater Ecology, 42 FREShWATER BIOLOGY 131, 132 (1999). See generally NAT'L RES. COUNCIL, FACILITATING INTERDISCIPLINARY RES. (2005); Warren Gold, Kern Ewing, John Banks, Martha Groom, Tom Hinckley, David Secord, \& Daniela Shebitz, Collaborative Ecological Restoration, 312 SCIENCE 1880, 1880 (2006) ("The complexity of the interface between human communities and ecological sustainability demands that we supersede our traditional, balkanized disciplines."); David W. Or, The Problem of Disciplines / The Discipline of Problems, 7 CONSERVATION BIOLOGY 10, 10 (1993) ("The great ecological issues of our time have to do in one way or another with our failure to see things in their entirety.").

134. Horst W.J. Rittel \& Melvin M. Webber, Dilemmas in a General Theory of Planning, 4 PoL'Y SCI. 155, 160-67 (1973).

135. See Doremus, supra note 2, at 332-33. 
should be divided among different users. People trained in different fields tend to define wicked problems and their solutions differently, ${ }^{136}$ in part because they are motivated by differing values but also because human beings are prone to exaggerate the importance of their own skills, and hence the skills of their disciplinary specialty. ${ }^{137}$

Disciplinary training also affects data interpretations. The meanings assigned to data depend upon the background of other knowledge against which they are seen, ${ }^{138}$ and people with different training bring different backgrounds. The value of particular experiments, and the relative importance of different types of error, will seem different through different disciplinary lenses, as the starkly divergent views taken by physical oceanographers and marine biologists of proposals for acoustic measurement of ocean temperatures in the 1980 s demonstrate. ${ }^{139}$ Only with both perspectives participating could a full view of the pros and cons of the proposed measurements emerge.

\section{Distribution}

Distribution is the transmission of data, knowledge, or information (before or after the refining and blending steps) to others. Distribution is critical to the scientific enterprise itself, as well as to the effective use of science in policy. As James Secord puts it, science is "knowledge in transit." 140 Yet the circulation of knowledge is no more automatic than its creation. Distribution can occur through publication in journals or as white papers, circulation of drafts, presentations at conferences, postings on web pages, and conversations. Obviously, information has to reach decision makers in order to be used. But reaching other audiences can also be important. Communication is an essential step in the scientific process itself, because it allows other scientists to test, extend, refute, and modify earlier findings or conclusions. ${ }^{141}$

136. See generally Sharachchandra Lélé \& Richard B. Norgaard, Practicing Interdisciplinarity, 55 BIOSCIENCE 967 (2005).

137. See Degnbol et al., supra note 69, at 534 (noting the tendency of disciplines to encourage "tunnel vision" in problem and solution framing); Andrew Sobel, Comments on Globalization, Interdisciplinary Research, Myopia and Parochialism, Government, Convergence, and Culture, 9 J. INT'L MGMT. 419, 421 (2003) (noting that academics who have chosen to focus on globalization tend to overstate the importance of global effects and underemphasize the influence of local processes).

138. See David N. Livingstone, Science, Text, and Space: Thoughts on the Geography of Reading, 30 TRANSACTIONS INST. BRIT. GEOGRAPHERS 391, 393 (2005) ("Readers come to texts with different reading histories, and read in the light of their literary genealogies. The meaning that any new work has for an individual reader is shaped by the other texts and theories and practices they have engaged. Meaning bleeds, as it were, from one text to another.").

139. See Daniel Sarewitz, How Science Makes Environmental Controversies Worse, 7 ENVTL. SCI. \& PoL'Y 385, 390-92 (2004) (noting that oceanographers thought the potential value of data from acoustic measurements outweighed the possibility of harm to marine mammals, but marine biologists disagreed).

140. See generally James A. Secord, Knowledge in Transit, 95 IsIs 654 (2004) (calling for historians of science to embrace the centrality to science of the circulation of knowledge).

141. See Scott L. Montgomery, The Chicago Guide to Communicating Science 1 (2002) ("Communicating is the doing of science."). 
In recent years, scientists at several federal agencies have complained that their superiors have deliberately inhibited broad communication of their results or scientific views. NASA climate scientist James Hansen made headlines when he charged that the Bush administration had tried to prevent him from speaking out about global warming after he gave a public lecture calling for $\mathrm{CO}_{2}$ emission reductions. ${ }^{142}$ Climate researchers at other agencies also report that they were told not to speak out or required to get clearance from their superiors before speaking to journalists. ${ }^{143}$ Perceptions of silencing extend to other natural resource scientists as well. A pair of surveys conducted by the Union of Concerned Scientists in 2005 revealed that close to half of the respondents at the Fish and Wildlife Service and NOAA Fisheries did not feel free to publicly express concerns about the conservation needs of species under their charge "without fear of retaliation." 144

The reluctance of federal agencies to share data relevant to resource management can extend not just to public communication but to requests by research scientists for data that could be used to evaluate management efforts. ${ }^{145}$ In part, this reluctance may spring simply from defensiveness and "reluctance to submit to the sometimes withering criticism of the peer review process," 146 a process to which agency personnel are not typically accustomed. The tendency to hold data close to the vest may be exacerbated in the case of high-profile resource conflicts by fear that outside studies might threaten management compromises that seem politically stable or undermine claimed management successes. Failure to provide full information to reviewers obviously can undermine the integrity and limit the usefulness of outside reviews. It can happen even where review is mandated by law or undertaken by advisory groups appointed by the agency itself. For example, in the course of deciding how to regulate

142. Andrew C. Revkin, Climate Expert Says NASA Tried to Silence Him, N.Y. TIMES, Jan. 29,2006 , at 1. NASA quickly undertook a review of its communication policies, and subsequently acknowledged that it had wrongly denied a media request to interview Hansen. Andrew C. Revkin, Scientists Commend NASA's Progress on Communications, N.Y. TIMES, Mar. 14, 2006, at 1; U.S. Federal News, NASA Admits Wrongdoing in Not Allowing Top Scientist to Discuss Climate Change Research, June 9, 2006, available at 2006 WLNR 9943137.

143. Juliet Eilperin, Climate Researchers Feeling Heat from White House, WASH. Post, Apr. 6,2000 , at A27.

144. Union of Concerned Scientists, SuRvey of U.S. Fish AND Wildlife SERVICE ECOLOGICAL SERviCES EMPLOYEES (undated), http://www.ucsusa.org/scientific_integrity/ interference/us-fish-wildlife-service-survey.html (29.2 percent of respondents disagreed and 12.8 percent strongly disagreed with the statement "Outside the agency I can openly express my concerns about the biological needs of species and habitats without fear of retaliation"); Union of Concerned Scientists, SURveY of NOAA FISHERIES SERVICE EMPLOYEes (2005), http://www.ucsusa.org/scientific_integrity/interference/survey-political-interference-at-noaa-fis heries.html (21.8 percent disagree and 17.7 percent strongly disagree with a similar statement). There are plenty of anecdotal stories suggesting that these fears are not without foundation. See, e.g., Fischman \& Meretsky, supra note 6, at 101 (scientist who had been critical of grizzly bear recovery program "had his office files removed, computer documents deleted, his mail screened, and his travel budget slashed").

145. See Fischman \& Meretsky, supra note 6, at 101 (noting difficulties outside scientist had in getting data for a study on grizzly recovery).

146. Id. at 96 . 
the herbicide atrazine, EPA convened two advisory committees of outside scientists but asked each only to consider a small fraction of the information EPA had available. In that way, EPA was able to skew the reviews so that they seemed to provide credible outside support for EPA's policy choice. ${ }^{147}$

Legislators from both parties have expressed concern about restrictions on communication of agency science. Democrats have asked the Government Accountability Office (GAO) to investigate allegations of silencing, ${ }^{148}$ and have introduced legislation to protect agency scientists from censorship or tampering with their scientific work. ${ }^{149}$ Republican Senator John McCain asked the National Science Board, which provides independent advice to the National Science Foundation (NSF), to examine federal agency policies concerning the suppression or distortion of scientific research findings. The Board responded that no uniform policy exists, and recommended that all federal research agencies "establish policies and procedures to encourage open exchange of data and results of research conducted by agency scientists, while preventing the intentional or unintentional suppression or distortion of research findings ...."150

Congress has itself contributed to limits on data transmission. In December 2000, it passed the Consolidated Appropriations Act of $2001^{151}$ with a brief rider known as the Information Quality Act (IQA). ${ }^{152}$ The IQA directed the Office of Management and Budget (OMB) to issue guidelines for "ensuring and maximizing the quality, objectivity, utility, and integrity of information . . . disseminated by Federal agencies." ${ }^{153}$ Agencies must also provide an administrative procedure for review of information alleged not to meet the IQA's standards. ${ }^{154}$ Information is clearly "disseminated" if it is posted on the agency's web site or incorporated into a publication or brochure. The Office of Management and Budget (OMB) believes information is also "disseminated" for purposes of the IQA if it is used in the course of a rulemaking proceeding. ${ }^{155}$ There is no way to reliably tell how much the IQA has

147. Jennifer Beth Sass and Aaron Colangelo, European Union Bans Atrazine, While the United States Negotiates Continued Use, 12 INT'L J. Occupational HealTH 260, 265 (2006).

148. Press Release, Wu Requests GAO to Investigate Scientific Manipulation \& Censorship, (May 2, 2006), http://www.house.gov/apps/list/press/or01_wu/pr05022006GAO.html; Press Release, Mikulski Says Integrity of Federal Science Agencies Must Not Be Compromised, (Feb. 17, 2006), http://mikulski.senate.gov/record.cfm?id=251712.

149. Restore Scientific Integrity to Federal Research and Policymaking Act, H.R. 839, 109th Cong. (2005). Democrats in the House Committee on Science fell just short in a recent attempt to add much of the language of Waxman's bill to H.R. 5450, a proposed organic act for the National Oceanic and Atmospheric Administration. House of Representatives, Committee on Science, Democratic Caucus, Press Release, Committee Reports NOAA Organization Bill Again, (June 14, 2006), http://sciencedems.house.gov/press/PRArticle.aspx?NewsID=1141.

150. Memorandum to Members of the National Science Board, Major Actions and Approvals at the May 10, 2006 Meeting, NSB-06-60, May 12, 2006, Attachment 4, http://www.nsf.gov/nsb/meetings/2006/0509/major_actions.pdf.

151. 44 U.S.C. $\$ 3516(2000)$.

152. Id. § 3516(a).

153. Id.

154. Id. $\S 3516(\mathrm{~b})(2)(\mathrm{B})$.

155. Guidelines for Ensuring and Maximizing the Quality, Objectivity, Utility, and Integrity of Information Disseminated by Federal Agencies; Republication, 67 Fed. Reg. 8451, 8460 
affected federal data communication. Most administrative IQA challenges have been unsuccessful, ${ }^{156}$ and federal courts have held that the IQA provides no private right of action. ${ }^{157}$ Only a few instances of removal of information from the public record following IQA challenges have been documented, ${ }^{158}$ and in a handful of other cases IQA complaints have apparently led to the addition of more information. ${ }^{159}$ Because the IQA imposes pre-dissemination requirements and raises the specter of potential post-dissemination challenge, however, it is possible that agencies are self-censoring, conserving their resources by choosing not to disseminate information they think might be challenged. ${ }^{160}$ Whatever its impact, the IQA approach may be spreading. As of 2004, the Congressional Research Service reported that Wisconsin had adopted legislation similar to the IQA, and other states were planning to do so. ${ }^{161}$

Outside researchers can also contribute to distribution shortfalls. The culture and reward system of academic science may make researchers reluctant to share preliminary data before they have had the opportunity to fully analyze it themselves, and to document their analysis in peer-reviewed publications. ${ }^{162}$ That process can be slow, both before and after submission of manuscripts. Refusing to release data until formal publication, therefore, can substantially delay communication.

Communication is not simply the responsibility of the creator or the refiner of information. End users of information should be active seekers. Regulators, for example, can reasonably be expected to conduct thorough searches of the peerreviewed literature, which is available to anyone with the expertise to search it and good library access. Sometimes there are shortfalls even at this fairly rudimentary search level, perhaps because agencies are under time pressure, have limited personnel, do not offer sufficient training, or do not have ready access to library resources.

(Feb. 22, 2006). Some knowledgeable commentators disagree. Sidney A. Shapiro, The Information Quality Act and Environmental Protection: The Perils of Reform by Appropriations Rider, 28 WM. \& MARY ENVTL. L. \& POL'Y REV. 339, 363-67 (2004).

156. See OFFICE OF MANAGEMENT AND BUDGET, OFFICE OF INFORMATION AND REGULATORY AFFAIRS, INFORMATION QUALITY: A REPORT TO CONGRESS, FISCAL YEAR 2003, at 8, available at http://www.whitehouse.gov/omb/inforeg/infopoltech.html\#iq [hereinafter OMB, 2003 REPORT].

157. Salt Inst. v. Leavitt, 440 F.3d 156 (4th Cir. 2006).

158. See Curtis W. Copeland \& Michael Simpson, The Information Quality ACT: OMB's GUIDANCE AND INITIAL IMPLEMENTATION 16-17 (Updated Sept. 17, 2004), available at http://www.ombwatch.org/info/dataquality/ RL32532_CRS_DQA.pdf (reporting that the National Institute on Aging changed its website and printed publications, eliminating statements that smokeless tobacco was as dangerous as cigarettes); Johnson, supra note 18, at 43 (reporting that EPA "removed a soil database from the Internet" in response to an IQA challenge).

159. Copeland \& Simpson, supra note 158 , at 12-13.

160. In a report to Congress on the first year of the IQA's operation, OMB asserted that it had no evidence that the IQA had reduced the number of agency information disseminations. OMB, 2003 REPORT, supra note 156, at 10. OMB Watch, in a response to OMB's report, pointed out that there was equally no evidence that agency disseminations had not been chilled, and reason to suspect that the resource-intensive IQA process might be chilling agency communication of information. OMB WATCH, THE REALITY OF DATA QUALITY ACT's FIRST YEAR: A CORRECTION OF OMB'S REPORT TO CONGRESS 10-11 (July 2004).

161. Copeland \& Simpson, supra note 158 , at 17.

162. See Fischman \& Meretsky, supra note 6, at 93-94 (explaining reluctance to release preliminary results). 
Shortfalls in information location by managers can sometimes be corrected by participants in the regulatory process, who have incentives and opportunity to bring relevant literature to the attention of regulators. But if the treasure hunt is more difficult, end users and stakeholders may be unable to find relevant information even with a diligent, well-financed search. Unfortunately, much information that is extracted and refined is never archived in a way that makes it available for management efforts.

Management agencies themselves are prime offenders. Millions of federal dollars are spent every year to generate environmental assessments and environmental impact statements, which contain background information on a wide variety of systems, as well as predictions which could be tested in retrospect. Those documents effectively disappear into a bookcase or file cabinet after the decision is made to take or not take the specific action they evaluate. Although we are well into the "information age," no centralized database collects environmental documents so that future researchers and managers can learn from them. ${ }^{163}$ Even in California, where by law environmental impact assessments must be submitted to a state clearinghouse, they are not maintained in any form readily available to the public. ${ }^{164}$ Other environmental documents are similarly unavailable. No database archives habitat conservation plans or biological opinions prepared under the Endangered Species Act, for example. Like environmental assessments, some of these documents are available on a hit-or-miss basis over the internet, particularly when they are first prepared, but there is no way to systematically search for or through them without making a series of pilgrimages to the offices where they were prepared. Even for those motivated to make such pilgrimages, there is no guarantee that copies of documents will be available promptly, or even that the responsible offices will have complete documents on hand. ${ }^{165}$

The systematic failure to archive resource management and environmental documents, a task that should be relatively easy given modern electronic tools, is a major leak in the information supply pipeline, spilling useful information out before it can reach those who might use it. Among other things, this particular leak forces resource managers to repeatedly re-invent the wheel, makes retrospective evaluations of prior actions virtually impossible, complicates the discovery and evaluation of cumulative impacts, and keeps forecasting techniques from advancing.

Distribution requires not only the transmission of information, but its transmission in a form accessible to and useful for the recipient. Depending upon the audience, it may be essential that the presentation clearly address key management questions. ${ }^{166}$

163. Daniel A. Farber, Bringing Environmental Assessment into the Digital Age, 10-16 (2006), UC Berkeley Public Law Research Paper No. 877625, available through Social Science Research Network at http://papers.ssm.com/sol3/papers.cfm?abstract_id=877625.

164. Id. at $12-13$.

165. In the course of a recent study of habitat conservation plans, my co-authors and I found that the documentation for fully one-third of them was not complete even at the regional Fish and Wildlife Service office that had approved them. See Matthew Rahn et al., Species Coverage in Multi-Species Habitat Conservation Plans: Where's the Science?, 56 BIOSCIENCE 613, 614 (2006).

166. See, e.g., NAT'L Res. COUNCIL, COMMITTEE TO IMPROVE THE U.S. GEOLOGICAL SURVEY Nat'l Water Quality AsSessment Program, Opportunities to IMProve the U.S.

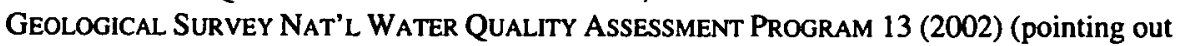
that explicit answers to key questions about the nation's water quality would be "particularly 
Managers often find it difficult to point researchers in useful directions, because they may not have the training or experience to determine which fields, approaches, or techniques will prove most useful. ${ }^{167}$ At the same time, researchers may show limited interest in real-world problems, and typically are not trained to translate their data into management-useful information. ${ }^{168}$

\section{Consumption}

Finally, there is the consumption stage, the actual use of knowledge to make, modify, or rescind management decisions. It might seem like consumption should follow automatically if information is adequately refined and distributed to the decisionmaker in a timely manner. Unfortunately, even at this step there is considerable room for slippage.

It is important to note at the outset that decisions that do not follow the recommendations of scientific advisors do not necessarily represent failures of consumption. Conservation is rarely if ever the only societal goal to be considered. In some cases, decision makers may simply decide that other goals, including economic efficiency, some vision of fairness, or even public distaste for necessary conservation measures, outweigh conservation of the resource. So, for example, land managers in the Channel Islands might decide not to implement lethal control measures against golden eagles, even though they understand the potential for eagles to eradicate the island fox. Or Great Britain might not change its badger-culling strategy, even though according to a scientific advisory group that strategy "cannot contribute constructively to the control of bovine TB." 169 I am not defending such decisions. They may be incorrect in a variety of ways. They may well represent failures to fully or correctly articulate societal values and goals, failures of the political process, or failures of institutions to hold policy actors to their assigned tasks. Even if they are "wrong," by some or all of these measures, however, decisions made with access to and consideration of all reasonably available data cannot be classified as failures to put informational fuel in the tank.

Consumption failures are situations in which information is ignored, misinterpreted, or not given appropriate weight despite being put before decision makers in a timely fashion. The most extreme version is flat out refusal to consider relevant information. As Director of the Fish and Wildlife Service's Southwestern Regional Office, Dale Hall (now Director of the entire Service), issued a memorandum limiting the use of genetic data in endangered species recovery planning. ${ }^{170}$ The memo was widely interpreted as forbidding any consideration of advances in understanding of the species' genetics after its listing. ${ }^{171}$

valuable to Congress, policy makers, resource managers, and the public.").

167. Peter W. Cullen et al., Collaboration in Scientific Research: A Critical Need for Freshwater Ecology, 42 FreShWATER BIOLOGY 131, 136 (1999).

168. Id.

169. INDEPENDENT SCIENTIFIC GROUP ON CATTLE TB, Report of the Work of the Group \& Its Published Findings, 2-3 (2005).

170. Memorandum from H. Dale Hall to Assistant Regional Director, Ecological Services, Albuquerque, N.M., Policy on Genetics in Endangered Species Activities (Jan. 27, 2005), available at http://www.peer.org/docs/fws/05_24_5_hallmemo.pdf.

171. See Felicity Barringer, New Rules on Endangered Species in the Southwest, N.Y. 
The genetics memo could be the tip of the iceberg in what seems to be a growing phenomenon: the import of an extreme interpretation of the Supreme Court's Daubert ${ }^{172}$ decision to the internal decision-making processes of administrative agencies. In Daubert, the Court directed federal judges to take on a stronger gatekeeping function for expert scientific testimony in order to ensure that any scientific evidence put before a jury is both relevant and reliable. Daubert emphasized that the judicial inquiry must be flexible, but listed several factors judges might consider, including whether the relevant technique or theory is testable, whether it has been subject to peer review and publication, its known or potential error rate, and its degree of acceptance within the scientific community. ${ }^{173}$ The Daubert standard is specific to the courtroom, both as a matter of law and as a matter of principle. As a matter of law, the Court derived the Daubert test from the Federal Rules of Evidence, which apply only to litigation in federal courts. ${ }^{174}$ As a matter of principle, the Court recognized that its Daubert rule might not always advance the search for truth, ${ }^{175}$ but essentially concluded that juries are not equipped to carry out the search for scientific truth and must be protected against exposure to evidence that could provide an excuse for irrational decisions. ${ }^{176}$

TIMEs, May 24, 2005, at A13 ("Dale Hall ... said that all decisions about how to return a species to robust viability must use only the genetic science in place at the time it was put on the endangered species list ... . even if there have been scientific advances in understanding the genetic makeup of a species and its subgroups in the ensuing years."); Letter to Dale Hall, Policy on Genetics in Endangered Species Activities (June 20, 2005), available at http://www.ucsusa.org/assets/documents/scientific_integrity/GeneticsLetter-1.pdf ("As time passes scientists typically obtain better knowledge of the threats facing endangered species and the conservation actions needed to recover them .... [The Service] would be remiss in its scientific duty if it ignored this scientific knowledge simply because it was not known at the time of or discussed in the listing rule ... [T] he preclusion by policy fiat of the large body of scientific information, in genetic or population-based conservation strategies will often prevent recovery teams and the Service from using the best available scientific information."); Letter from Ralph O. Morgenweck, Regional Director, Region 6, to Regional Director, Region 2, Policy on Genetics in Endangered Species Activities (Mar. 11, 2005), available at http://www.peer.org/docs/fws/05_24_5_morgenweck.pdf ("Limiting the Fish and Wildlife Service's ability to base recovery criteria on the protection of genetic variation contradicts requirements for the Service to use the best available science in decision making. We often discover new information about the biology of a species after its listing .... Restricting the use of genetic information discovered after the final listing unnecessarily restricts the Service's ability to design a recovery plan that would best conserve the species.").

172. Daubert v. Merrell Dow Pharmaceuticals, Inc., 509 U.S. 579 (1993).

173. Id. at 593-94.

174. The Court derived its test from Federal Rules of Evidence 402 and 702. Id. at 589, 597. Rule 702 has been amended since the Daubert decision, in a way that may or may not codify it. See Anthony Z. Roisman, Procedural Aspects of Daubert, Environmental and Toxic Tort Litigation, ALI-ABA CLE Course of Study, Jan. 26-27, 2006, available on Westlaw at SL080 ALI-ABA 101 ("Essentially, all the 2000 amendment has done is introduce more confusion into a subject that clearly did not need it.").

175. Daubert, 509 U.S. at 596-97.

176. I have speculated previously that the Daubert Court may have been trying to keep out evidence that is probably not right, based on an underlying assumption that juries are systematically inclined to favor injured plaintiffs over deep-pocket defendants in the kinds of tort cases that gave rise to Daubert. Holly Doremus, The Purposes, Effects, and Future of the 
Administrative agencies are not subject either to the Federal Rules of Evidence or to the irrationalities that many would say plague the jury system. Since Daubert came down, however, anti-regulatory interests have been trying to import it into the administrative arena. Some have argued that a Daubert-like approach should be used to pierce traditional deference to agency scientific decisions in judicial review, making judges actively police the scientific information on which agencies rely to defend their decisions. ${ }^{177}$ Given the doctrinal disjunction and the entrenched status of deference to technical decisions within the judiciary, I don't expect those arguments to enjoy wide success any time soon. ${ }^{178}$

Agencies can change their :nternal procedures more nimbly than the judiciary can alter precedent, however, and they have been under pressure to do so. The U.S. Chamber of Commerce, for example, has called for an Executive Order "to require federal agencies to apply Daubert standards in the administrative rulemaking process." 179 No such Executive Order has been forthcoming, but there are signs that some agencies are adopting an "exclusionary rule" for scientific evidence they perceive as not up to their stringent interpretation of the Daubert standards. When EPA began the process of revising its air quality criteria for lead, for example, it invited submission only of "research studies that have been published, accepted for publication, or presented at a public scientific meeting," 180 a standard that would exclude far more evidence than Daubert itself.

Although the Information Quality Act (IQA) directly addresses communication, it seems to have an indirect chilling effect on information consumption (as indeed it was probably intended to do). Wendy Wagner has described the IQA as imposing "an evidentiary screening process on regulatory agencies that looks very much like the courts' Daubert test." ${ }^{181}$ Stephen Johnson documents situations in which agencies faced with IQA challenges have altered or delayed substantive decisions on protection of endangered species, pesticide regulation, and guidance on asbestos risks. ${ }^{182}$ OMB Watch reports that the Mine Safety Health Administration decided to phase in a rule

Endangered Species Act's Best Available Science Mandate, 34 ENVTL. L. 397,414 (2004).

177. This argument has been made by environmental interests as well as foes of regulation. Patricia Smith King, Applying Daubert to the "Hard Look" Requirement of NEPA: Scientific Evidence Before the Forest Service in Sierra Club v. Marita, 2 WIs. ENVTL. L.J. 147 (1995); Paul S. Miller \& Bert W. Rein, "Gatekeeping" Agency Reliance on Scientific and Technical Materials After Daubert: Ensuring Relevance and Reliability in the Administrative Process, 17 TOURo L. Rev. 297 (2000); Alan Charles Raul \& Julie Zampa Dwyer, "Regulatory Daubert," A Proposal to Enhance Judicial Review of Agency Science by Incorporating Daubert Principles Into Administrative Law, 66 LAW \& CONTEMP. PROBS. 7 (2003).

178. Even in the courts, the Daubert pendulum may have swung too far. According to one recent study, "courts are now asking doctors who testify as experts to meet standards that exceed those that the doctors use to diagnose and treat their own patients." David Michaels \& Celeste Monforton, Scientific Evidence in the Regulatory System: Manufacturing Uncertainty and the Demise of the Formal Regulatory System, 13 J.L. \& POL'Y 17, 39 (2002) (citing Jerome P. Kassirer \& Joe S. Cecil, Inconsistency in Evidentiary Standards for Medical Testimony: Disorder in the Courts, 288 J. AM. MED. Ass'N 1382, 1382-87 (2002)).

179. U.S. Chamber of Commerce, Scientific Information in Federal Rulemaking, http://www.uschamber.com/issues/index/regulatory/scientific_rulemaking.htm .

180. EPA, Air Quality Criteria Document for Lead, 69 Fed. Reg. 7835 (Nov. 9, 2004).

181. Wagner, supra note 75 ,at 590-91.

182. Johnson, supra note 18 , at $43-44$. 
intended to protect miners from exposure to diesel emissions over six years, instead of one, after an IQA challenge. ${ }^{183}$ Such reports, of course, provide only limited information. They do not reveal whether the IQA challenges brought real weaknesses in the information to the attention of regulators, or instead bullied regulators into ignoring useful information.

Even without formal IQA or Daubert-type barriers, regulators sometimes shy away from considering relevant information. In 2002, for example, the National Marine Fisheries Service (NMFS, now known as NOAA Fisheries) had to decide whether or not to list killer whales (Orcinus orca) in the Puget Sound area as an endangered or threatened "distinct population segment." ${ }^{184}$ That decision required NMFS to make a judgment about orca taxonomy, because according to agency policy a distinct population segment must be significant "to the species to which it belongs." 185 The taxonomic community, at the time of the decision and today, formally recognizes only one, global, species of killer whale. According to NMFS scientists, however, that taxonomy is outdated and does not accurately reflect the biology of the killer whale. NMFS' scientific review team found that at least two taxa should be recognized in the North Pacific. ${ }^{186}$ Nonetheless, NMFS used the global species as the comparison taxon. Not surprisingly, it found that the Puget Sound whales were not significant to that taxon. Accordingly, it declined to list the whales. ${ }^{187}$ A cynical explanation is that NMFS was simply looking for an excuse to avoid listing the Puget Sound whales, whose protection might bring restrictions on a variety of activities. But there may be more to it than that. Members of the NMFS review team agreed that the established taxonomy was wrong, but could not agree on what should replace it. ${ }^{188}$ Yet any decision not based on the old taxonomy would require NMFS to settle on an alternative. Faced with the difficult, and undoubtedly controversial, task of constructing an improved taxonomy, NMFS preferred to retreat to the shelter of a published standard, even one it knew to be wrong.

Failures of consumption may also occur because decision makers do not trust information. That can happen if the information comes from a source decision makers do not regard as credible, such as someone with a financial interest in the regulatory outcome, or if key stakeholders are excluded from the information production process. ${ }^{189}$ Nonconsumption, of course, is only problematic if the rejected information

183. OMB Watch, Industry Derails Labor Safety Rule with Data Quality Challenge, http://www.ombwatch.org/article/articleview/3161/1/231?TopicID=1.

184. The ESA allows the listing of species, subspecies, and distinct population segments of vertebrate species. 16 U.S.C. § 1532(16).

185. Policy Regarding the Recognition of Distinct Vertebrate Population Segments Under the Endangered Species Act, 61 Fed. Reg. 4722, 4725 (Feb. 7, 1966).

186. Center for Biological Diversity v. Lohn, 296 F. Supp. 2d 1223, 1232-33 (W.D. Wash. 2003), vacated as moot, 483 F.3d 984 (9th Cir. 2007).

187. Id. at 1233. The District Court remanded that decision, ruling that reliance on the outdated taxonomy violated the ESA's requirement that listing decisions be made on the basis of the best available scientific information. Id. at 1236-37.

188. Four different possibilities for taxonomic revision received roughly equal support within the review team. Id. at 1233.

189. See, e.g. Cash et al., supra note 25 (explaining that information will not be used in decisions unless it is regarded as credible, legitimate, and salient); David W. Cash, Innovative Natural Resource Management: Nebraska's Model for Linking Science and Decision Making, 
is in fact reliable, or at least more reliable than other sources. But regulators who find themselves faced with dueling studies championed by impassioned advocates may be paralyzed. Suspicion of the motives of the advocates may carry over to suspicion of the substance of the information they are pushing. ${ }^{190}$

Finally, information will only be used effectively if decision makers have the capacity to properly evaluate it. In part, this problem can be addressed by careful refining and communication, but in some circumstances there is no substitute for agency personnel with the ability to perceive the significance of information for their regulatory responsibilities and goals. ${ }^{191}$ Those personnel must be given adequate time to find and evaluate information. The strict deadlines that apply to many regulatory actions under the ESA, for example, combined with inadequate staffing, can make it very difficult to fully evaluate and make good use of all available information.

\section{REPAIRS AND PREVENTIVE MAINTENANCE}

What lessons should we draw from this tour through the steps in the information supply chain? At the most general level, it's helpful to recognize that the information gap problem (like most policy problems) is not monolithic and therefore is not likely to be susceptible to any single universal fix. Diagnosing and repairing problems is hard, context-specific work. It is not enough for managers to say simply "we need more information" and pass the buck to scientists, or for that matter for scientists to say "you're not taking our advice" and pass the buck the other way.

Although it's not easy, neither is the situation hopeless. It's not the case that the current existence of information gaps necessarily means that we can't bring scientific information to bear, or that we are doomed to simply wait and hope for new

ENVIRONMENT, Dec. 2003, at 8, 15-16 (noting that Nebraska model provided credible, policyrelevant scientific output by combining input from hydrologists, geologists, economists, crop scientists, farmers, and water users with modeling expertise of U.S. Geological Survey).

190. Opposing sides in environmental and natural resources disputes these days regularly accuse each other's technical experts of "advocacy science," in which the conclusion is predetermined and the evidence selectively cited or interpreted to match. Funding can drive advocacy science; Sheldon Krimsky cites studies providing evidence that funding sources are correlated with conclusions in drug studies. Sheldon Krimsky, The Funding Effect in Science and Its Implications for the Judiciary, 13 J.L. \& PoL'Y 43, 57-61 (2005). In the natural resources context, deep commitment to a conservation outcome, stubborn attachment to one's initial interpretation, and political leanings of whatever stripe are all suspected of driving data interpretation. See Michael S. Cooperman \& Douglas F. Markle, The Endangered Species and the National Research Council's Interim Judgment in Klamath Basin, 28(3) FISHERIES 10 (Mar. 2003) (providing one example of an exchange of polite accusations); William M. Lewis, Jr., Klamath Basin Fishes: Argument is No Substitute for Evidence, 28(3) FISHERIES 20 (Mar. 2003). Recognizing their own conservation bent and the effect that bias can have both on data interpretation and on the perception of proffered scientific advice, conservation biologists have long exhorted their fellows to put the classical scientific method front and center. See, e.g., Dennis D. Murphy, Conservation Biology and Scientific Method, 4 Conservation BIologY 203 (1990). In fact, there is no strong line between "real science" and "advocacy science." Interpretations of uncertain data are always affected to some degree by the scientific, political, and other views of the interpreter.

191. Cf. U.S. EPA SCIENCE AdVISORY BOARD, supra note 54, at 2 (calling for EPA to "enhance its technical capacity to evaluate the links among global climate change and its mandated responsibilities"). 
discoveries. It is worth making the effort to diagnose problems because there may be practical steps that can be taken to bridge, or at least narrow, information gaps.

A number of such steps could be helpful across a variety of contexts. It is sobering to note, though, that even in the oil industry, with billions of dollars at stake, basic repairs and maintenance can be ignored. ${ }^{192}$ For natural resource management, where government agencies are always financially strapped and the absence of information often favors private economic interests, no one should be under the illusion that it will be easy to institute a more effective maintenance regime for the information pipeline.

\section{A. Recognize the Limits of Scientific Information}

The first step in improving the use of scientific information in natural resource decisions is for scientists, managers, and the interested public to recognize the limits of what scientific information can contribute to those decisions. That sounds simple, but it apparently is not. Although commentators have long recognized that science cannot be the only input to resource management, unrealistic expectations of science continue to plague resource conflicts.

Many resource questions are fundamentally questions of values not susceptible to scientific resolution. Questions of "how much is enough" to conserve, often the most challenging issues for managers, fall in this category. Science can, at least in theory, identify minimum viable populations, the threshold that must be protected if a species is to survive. But above that threshold, science cannot tell society, for example, how many gray wolves, occupying how much of their historic range, are enough, ${ }^{193}$ or what balance should be struck between habitat preservation and development. Questions of what should be conserved also fall into this category. Science can highlight distinctions between hatchery and wild-born salmon, ${ }^{194}$ or between populations of killer whales, ${ }^{195}$ but cannot answer which should be preserved or at what cost.

192. After BP shut down its Prudhoe Bay operations in August 2006 due to severe corrosion in pipelines, company officials said that they had spot checked pipelines but had not run a "smart pig" through to examine the entire length of the lines since 1992. Complete inspections had not been done even after a series of tests ordered by government officials revealed corrosion at a number of points. Clifford Krauss \& Jeremy W. Peters, Biggest Oil Field in U.S. Is Forced to Stop Pumping, N.Y. Times, Aug. 8, 2006, at A1.

193. Whether the gray wolf should be delisted has been controversial because although populations are increasing in the Northern Rockies and Great Lakes areas, the vast majority of the wolf's historic range in the contiguous United States remains unoccupied. See, e.g., Defenders of Wildlife v. Sec'y, U.S. Dep't of the Interior, 354 F. Supp. 2d 1156 (D. Or. 2005) (overturning rule downlisting gray wolf to threatened over most of its historic range). Since that decision, FWS has delisted the wolf in its two strongholds, the Western Great Lakes and Northern Rockies. Final Rule Designating the Western Great Lakes Populations of Gray Wolves as a Distinct Population Segment; Removing the Western Great Lakes Distinct Population Segment of the Gray Wolf From the List of Endangered and Threatened Wildlife, 72 Fed. Reg. 6052 (Feb. 8, 2007) (codified at 50 C.F.R. 17.11); Final Rule Designating the Northern Rocky Mountain Population of Gray Wolf as a Distinct Population Segment and Removing This Distinct Population Segment From the Federal List of Endangered and Threatened Wildlife, 73 Fed. Reg. 10,514 (Feb. 27, 2008) (to be codified at 50 C.F.R. 17.11).

194. For an independent panel report requested by NOAA Fisheries, see JODY HEY ET AL., Considering Life History, Behavioral, and Ecological Complexity in Defining 
Looking to science to articulate societal values can only result in frustration and controversy. Consider, for example, the dispute over regulatory protection of the Preble's meadow jumping mouse (Zapus hudsonius preblei). Designated as a subspecies in the 1950 s based on skull measurements, the Preble's meadow jumping mouse was listed as threatened in $1998 .{ }^{196}$ That listing, which potentially complicates development in Wyoming and along the rapidly urbanizing Front Range of the Rocky Mountains in Colorado, has brought strenuous opposition and spawned a bitter scientific dispute. Dr. Rob Roy Ramey, a scientist at the Denver Museum of Nature and Science, concluded on the basis of a genetic study that the Preble's mouse belonged in the same subspecies as the abundant Bear Lodge jumping mouse of Montana and South Dakota. ${ }^{197}$ Ramey testified before Congress that his study, which was financed in part by the state of Wyoming, highlighted the need to set higher scientific standards for ESA implementation. ${ }^{198}$ In response to a petition submitted by Wyoming and relying heavily on Ramey's work, FWS proposed to delist the Preble's meadow jumping mouse. ${ }^{199}$ After getting conflicting opinions from fourteen scientists it had asked to review Ramey's work, FWS commissioned a new genetic study by USGS scientist Tim King. Using slightly different methods, King affirmed the earlier taxonomy, concluding that the Preble's mouse was genetically distinct from other subspecies. ${ }^{200}$ Wyoming sought a third opinion from a biologist at Brigham Young University, who concluded that there were "differences between the Preble's and Bear Lodge mice, but not enough to justify their description as two subspecies." ${ }^{201}$ New studies appeared, King and Ramey traded ugly comments, ${ }^{202}$ and FWS eventually empanelled an expert advisory body to sort it all out. ${ }^{203}$ The panel determined that the Preble's mouse was a valid subspecies under most definitions, ${ }^{204}$ but of course that was never really the fundamental question.

Conservation Units For Pacific SAlmon (June 13, 2005), http://www.nwfsc.noaa.gov/trt/regarding_salmon_esus.pdf.

195. See Ctr. for Biological Diversity v. Lohn, 296 F. Supp. 2d 1223 (W.D. Wash. 2003).

196. Final Rule to List the Preble's Meadow Jumping Mouse as a Threatened Species, 63

Fed. Reg. 26,517 (May 13, 1998) (to be codified at 50 C.F.R. pt. 17). The available genetic studies at the time of listing were consistent with recognition of the subspecies. Id. at 26521.

197. Rob Roy Ramey II et al., Genetic Relatedness of the Preble's Meadow Jumping Mouse (Zapus Hudsonius Preblei) to Nearby Subspecies of Z. Hudsonius as Inferred from Variation in Cranial Morphology, Mitochondrial DNA and Microsatellite DNA: Implications for Taxonomy and Conservation, 8 ANIMAL CONSERVATION 329 (2005).

198. Kirk Johnson, Debate Swirls Around the Status of a Protected Mouse, N.Y. TIMES, June $27,2004, \S 1$, at 16 .

199. Twelve-Month Finding on a Petition to Delist the Preble's Meadow Jumping Mouse (Zapus Hudsonius Preblei) and Proposed Delisting of the Preble's Meadow Jumping Mouse, 70 Fed. Reg. 5404 (proposed Feb. 2, 2005) (to be codified at 50 C.F.R. pt. 17).

200. Tim L. King et al., Comprehensive Genetic Analyses Reveal Evolutionary Distinction of a Mouse (Zapus Hudsonius Preblei) Proposed for Delisting from the U.S. Endangered Species Act, 15 MoleCUlar ECOLOGY 4331 (2006).

201. Peter Aldhous, The Mouse that No One Can Ignore, NEw SCIENTIST, July 15, 2006, at 12 .

202. King accused Ramey of making a systematic error. Ramey responded that, "Tim King's station in life seems to be to do scientific colonoscopies." Jim Erickson, Biologists Pelt One Another over Mouse, RocKY MTN. NEws, June 21, 2006, at A12.

203. Aldhous, supra note 201.

204. SUSTAINABLE ECOSYSTEMS INST., EVALUATION OF SCIENTIFIC INFORMATION REGARDING 
The Preble's mouse saga illustrates the difference between data and information, and the role of nonscientific input in making that leap. The information needed to inform the management decision to list the Preble's meadow jumping mouse or not is whether the Preble's mouse is different from others in ways that justify its protection. Genetic and morphometric data can highlight differences, but they don't tell decision makers which differences matter, or how much difference is enough to justify different conservation treatment. Putting aside the disagreements about who has the better data, taxonomic "lumpers" and "splitters" could look at the exact same data and come to different classification conclusions. Before managers can make effective use of data, or even understand what types of data are relevant to their decision, they need a clearer understanding of the conservation goals they are supposed to be pursuing.

It is also important to recognize the difficulties inherent in producing some types of scientific data, or in producing information that is absolutely beyond doubt. As one of several National Research Council committees tasked with examining various aspects of Columbia River salmon management has explained:

Substantial resources have been devoted to investigating Columbia River salmon, and today these fish species are one of the most intensively studied in the United States, if not the world. Although scientific understanding of the salmon has improved over the decades, perfect understanding of all factors and relationships that affect salmon life cycles is beyond current and foreseeable future scientific means.

More precise scientific information regarding salmon behavior, environmental influences, and rates of survival could, over time, no doubt be obtained. However, significant resources are now being devoted to this pursuit, as federal and state scientists and scientists from universities and regional consultancies are involved in extensive salmon research programs. One task pursued in this study concerned the identification of knowledge "gaps" and "scientific information" needed to develop comprehensive strategies for recovering and sustaining listed species and managing water resources to meet human needs . . . . This task, however, presupposes that sound management strategies can be devised only when scientific "gaps" are filled and that it is possible to determine a priori the scientific information that will lead to better management decisions. Such suppositions do not reflect contemporary natural resources management realities and the relationships between scientific information and decision making processes. ${ }^{205}$

Demanding perfection of scientific information is a recipe for paralysis by analysis. Interests favored by the status quo might well prefer that approach, but it will rarely be conducive to effective conservation. Managers must evaluate, to the best of their ability, the likelihood of obtaining desired scientific information at a reasonable cost within a reasonable time frame. Decisions about how to handle uncertainty should take into account the reducibility or irreducibility of that uncertainty, as well as the risks and costs of various types of error.

Preble's MEADOw JUMPING MOUSE (2006), http://www.fws.gov/mountainprairie/species/mammals/preble/Prebles_SEI_report.pdf.

205. COMm. ON WATER Res. Mgmt., Instream Flows, and Salmon SuRvival IN THE Columbia River basin, Nat'l Research Council, Managing the Columbia River: INSTREAM FLOWS, WATER WITHDRAWALS, AND SALMON SURVIVAL 186-87 (2004). 


\section{B. Set Priorities}

That leads to the next lesson. The most important leaks in the information supply line should be addressed first, and efforts to gather, distribute, and use scientific information should be tailored to the value that information has to the decisions being made. Like oil exploration and extraction, scientific research and data gathering are capital-intensive and risky ventures. Their high costs and uncertain benefits call for some attempt at a crude cost-benefit evaluation. Although it was once the prevailing practice, no oil company today could justify to its shareholders randomly poking holes in the earth, even in the vicinity of proven reserves, or extracting resources that cannot economically be marketed and used. Such reckless expenditures should also be avoided in the information supply process.

Information-intensive management may itself require cost-benefit justification at the most general level. The direct costs of reflective resource management, in which managers try to forecast ex ante the impacts of management measures and monitor those impacts ex post to refine their forecasting ability, are necessarily higher than those of the current prevailing practice of pursuing an intuitive best guess without follow-up. Proponents of the former strategy should be prepared both to articulate its long-term benefits, which should include a higher likelihood of conservation success and financial savings over the long run because mistakes do not have to be undone or corrected, and to think seriously about how much of what type of information inputs are most useful up front and how back-end evaluation can be done most efficiently. More explicitly addressing these sorts of questions could address some of the political barriers to increased funding, helping legislators understand the value of information production and use in relation to that of uninformed action.

Evaluating the costs and benefits of information supply steps is not easy. As the NRC committee quoted above pointed out, it is tough to identify in advance the types of scientific information that will most help managers and, given the uncertainties of exploration, generally impossible to precisely calculate the cost of improved understanding of ecological systems. Nonetheless, rough priorities could probably be identified at two different levels, and the process of priority setting itself could help clarify both societal values and information shortfalls.

First, priority setting is needed at the very broadest levels, across the range of resource management problems, for both exploratory and extractive data production. In the United States, "[t]here is no overall mechanism to determine the most appropriate and highest priority investments in monitoring and reporting capacity," 206 or for that matter in basic exploratory research. As a result, research and monitoring efforts and funding are distributed $a d h o c$, primarily to the highest profile resource conflicts, with little or no thought given to the value of different potential studies. ${ }^{207}$

206. H. JOHN HEINZ III CTR. FOR SCI., ECON. \& THE ENV'T, FILLING THE GAPS: PRIORITY DATA NeEds and Key Management Challenges for National Reporting on Ecosystem CONDITION 4 (2006), http:/www.heinzctr.org/Programs/Reporting/Working Groups/Data Gaps/Gaps_LongReport_LoRes.pdf.

207. Spending on endangered species recovery, for example, varies widely across species. See, e.g., FWS FED. \& ST. ENDANGERED \& THREATENED SPECIES EXPENDITURES: FISCAL. YEAR 2004, 6 (2006), http://www.fws.gov/endangered/expenditures/reports/FWS Endangered Species 
Second, priority setting and explicit analysis of the value and feasibility of producing specific types of information are underutilized at a much narrower scale for individual resource management problems. As a result, large amounts of money may be spent on research and on management efforts without advancing knowledge of the system. It is hard to imagine a situation more likely to produce resentment of conservation efforts and political incursions into conservation budgets. Management of Columbia River salmon resources is probably the highest profile example of large expenditures without substantial advances in understanding. Direct federal expenditures for recovery of Columbia River salmon stocks were over $\$ 3$ billion dollars between 1982 and $2002,{ }^{208}$ yet the threats to those stocks remain poorly understood. Perhaps, as the excerpt above from the most recent NRC Columbia salmon report suggests, much of our remaining ignorance is due to the intractable nature of the scientific questions posed by salmon management. But surely not all of it-recall the failure to systematically study juvenile salmon barging, one of the major strategies relied upon by river managers to protect the fish. ${ }^{209}$ Other examples of substantial expenditures without documented learning are not hard to find.

Explicit analysis of priorities and the value of information would likely encourage two steps that are currently frequently skipped: formal decision analysis and postimplementation monitoring. The first is not costly, but tends to be omitted in the rush to implement those actions managers assume will be most beneficial. The second carries costs, but without it learning is nearly impossible. To cite just one example where skipping these two steps has kept learning at a virtual standstill, a 2002 GAO report found that after twenty-five years of research and management efforts to recover the Mojave Desert tortoise, at a cost of more than $\$ 100$ million, almost nothing was known about the status of the species, threats to its survival, or the effectiveness of management actions taken on its behalf. ${ }^{210}$ The primary culprits, according to the GAO, were lack of a considered research strategy and failure to monitor the effects of management steps. The first would highlight what is and is not known about the resource, and what knowledge has the greatest potential to influence management choices. It would also encourage the development of formal, even if simplistic, models

2004 Expenditures Report.pdf; J. Michael Scott, Leona K. Svancara \& Anna Pidgorna, By the Numbers, in Dale D. Goble, J. Michael Scott \& Frank W. Davis, EDS., The ENDANGered SPECIES ACT AT THIRTY: RENEWING THE CONSERVATION PROMISE 16 (2005). There is no overall planning process for determining expenditures. The differences do not disappear when expenditures are compared to the total costs of recovery estimated in recovery plans, and they do appear to correlate with species' status. Julie K. Miller, J. Michael Scott, Craig R. Miller \& Lisette P. Watts, The Endangered Species Act: Dollars and Sense?, 52 BIOSCIENCE 163 (2002). 208. U.S. Gen. ACCOUNTING Office, Columbia River Basin Salmon and Steelhead: FEDERAL AGENCIES' RECOVER RESPONSIBILITIES, EXPENDITURES AND ACTIONS 2 (2002).

209. See supra text accompanying notes 61-62. See also Mary H. Ruckelshaus, Phil Levin, Jerald B. Johnson \& Peter M. Kareiva, The Pacific Salmon Wars: What Science Brings to the Challenge of Recovering Species, 33 ANN. REV. OF ECOLOGY \& SYSTEMATICS 665, 685 (2002) ("The contents of salmon management plans thus appear to be guided by serendipitous treatment of these effects by scientists, rather than a more holistic biological vision of threats analysis."); id. at 690 ("Clearly, a widely agreed upon and supported strategic research plan is needed to organize guidance for salmon recovery efforts.").

210. See U.S. GEN. ACCOUNTING OFFICE, ENDANGERED SPECIES: RESEARCH STRATEGY AND Long-Term Monitoring Needed for the Mojave Desert Tortoise Recovery Program (2002). 
of the managed system, which facilitate oversight by increasing the transparency of management judgments. ${ }^{211}$

Priority setting appears to work best when it engages outside experts, and when there is a mechanism for overseeing its implementation. Without a mechanism for oversight, priority setting for research, just as for other management decisions, can easily become an empty exercise. For example, a priority-setting process was developed by Forest Service researchers for decisions about what to survey and monitor in connection with actions proposed under the Northwest Forest Plan. ${ }^{212}$ The researchers recognized that although the plan called for forest management to protect several hundred species, not every one could be actively managed, nor could the impacts of every proposed action on each be evaluated. They called for the setting of priorities, taking into account the extent of known or suspected risk to the species, its potential impact on management actions, and the ability to collect information efficiently and effectively. ${ }^{213}$ Those sound like reasonable factors to consider. However, it is not possible to evaluate how well this strategy has worked, or even if it has been implemented at all. No readily accessible database recounts the use of this strategy or its consequences. Indeed, not long after it was issued, the Bush administration decided to substantially cut back on the "survey and manage" strategy. ${ }^{214}$ As managers struggle to make the transition from nearly blind to reflective management, it is important that management strategies themselves be subjected to ongoing monitoring and especially to post-hoc evaluation, so that those that work best and most efficiently can be identified and replicated.

NMFS has also made some efforts toward priority setting, although so far those attempts appear half-hearted. In 1996, Congress ordered the Service to develop a strategic plan for fisheries research, to be revised every three years. ${ }^{215}$ An initial strategic plan was published in 1998, and updated in 2001 and $2004 .{ }^{216}$ The 2001 plan

211. See Shaffer et al., supra note 5, at 135. Explicit modeling, even at a very basic level, can also decrease the extent to which the judgments of scientific advisors or managers respond to their unconscious biases rather than to what is actually known about the system. Michael A. McCarthy, David Keith, Justine Tietjen, Mark A. Burgman, Mark Maunder, Larry Master, Barry W. Brook, Georgina Mace, Hugh P. Possingham, Rodrigo Medellin, Sandy Andelman, Helen Regan, Tracey Regan \& Mary Ruckelshaus, Comparing Predictions of Extinction Risk Using Models and Subjective Judgment, 26 ACTA OECOLOGICA 67 (2004).

212. See Randy Molina, Dan McKenzie, Robin Lesher, Jan Ford, Jim Alegria \& Richard Cutler, USDA Forest Serv., General Technical RePORt PNW-GTR-573, STrategic Survey Framework for the Northwest Forest Plan SuRvey and MaNage PROGRAM (2003).

213. See id. at 4-5 (referring to these as biological, managerial, and operational factors, and breaking them down into a number of more specific subfactors).

214. See Doremus, supra note 10 , at 294-96. That move has recently been scuttled by a federal court. Nw. Ecosystem Alliance v. Rey, No. 04-844P, 2006 WL 44361 (W.D. Wash., Jan. 9, 2006) (setting aside the 2004 Record of Decision and reinstating the 2001 Record of Decision and its survey and manage requirements); Nw. Ecosystem Alliance v. Rey, No. 04-844P, 2006 WL 1075213 (W.D. Wash., Apr. 20, 2006) (declining to reconsider the January decision).

215. 16 U.S.C. $\$ 1881$ c(b) (2000).

216. NAT'L MARINE FISHERIES SERV., U.S. DEP'T OF COMMERCE, NMFS STRATEGIC PLAN FOR FiSHERIES RESEARCH 10 (3d ed. 2004), http://www.st.nmfs.noaa.gov/st4/s_plan/2004/NMFSStrat-Plan-2004.pdf. 
contains a lengthy laundry list of general studies NMFS intends to engage in, without any attempt to set priorities, evaluate management usefulness, or assess resource demands. ${ }^{217}$ Its scope was limited to NMFS's own research facilities; it made no attempt to assess the availability or usefulness of independent academic, state, or other research efforts. It appears to have had little impact on management-relevant research needs, even within the agency that produced it. In 2004, a group of NMFS scientists published a paper calling for a coordinated research plan on the estuarine and marine phases of the Pacific salmon lifecycle. They noted that although several NMFS laboratories were involved in such research, there was no coordinated plan for organizing those activities, or for developing "mutually beneficial and synergistic research programs with universities, state agencies, and other government laboratories."218

A better model for priority setting comes from the California Bay-Delta Authority and emphasizes the importance of outside review of agency research priorities. The Bay-Delta Authority is the institutional successor of the short-lived state-federal CalFed program. ${ }^{219}$ While it has had its problems with funding and political acceptance, this program has made very strong efforts to systematize the development of new scientific information about the Bay-Delta and to incorporate that information into management decisions. From the outset, Cal-Fed included a science program as one of its core program elements. ${ }^{220}$ An Independent Science Board and other independent review panels were also part of the original Cal-Fed structure. ${ }^{221}$ In a very practical way, the creation of a single science program has facilitated effective priority setting: funding for Bay-Delta research and ecosystem restoration grants that had been scattered among a variety of agencies was suddenly both centralized and subject to independent review. ${ }^{222}$ In addition, the Independent Science Board has been a persistent force, urging the consideration of multiple disciplinary perspectives, recommending priorities for research, harping on the importance of monitoring, and pointing out problems with funding processes. ${ }^{223}$

Publicity about the lack of good science supporting expensive programs can also help push agencies toward real priority setting. Just a few years ago, the federal desert tortoise conservation program was in such disarray that it generated a GAO report

217. See NAT'l Marine Fisheries SeRv.,U.S. DeP'T of Commerce, NMFS STRATEgic Plan FOR FISHERIES RESEARCH (2d ed. 2001), available at http://www.govdocs.aquake.org/ cgi/reprint/2003/516/5160010.pdf.

218. Richard D. Brodeur, George W. Boehlert, Ed Casillas, Maxwell B. Eldridge, John H. Helle, William T. Peterson, William R. Heard, Steven T. Lindley \& Michael H. Schiewe, $A$ Coordinated Research Plan for Estuarine and Ocean Research on Pacific Salmon, FISHERIES, May 2000, at 7, available at http://www.nwfsc.noaa.gov/assets/2/ 3287_06172004_104126_salmonplan.pdf.

219. For a description of Cal-Fed's origin and structure, see Jody Freeman \& Daniel A. Farber, Modular Environmental Regulation, 54 DUKE L.J. 795, 837-57 (2005).

220. Calfed Bay-Delta Program, Programmatic Record of Decision 74 (2000).

221. Id. at 75 .

222. Freeman \& Farber, supra note 219 , at 865.

223. See, e.g., Memorandum from Tom Dunne, Chair \& Denise Reed, Vice Chair to $\mathrm{Cal}$. Bay-Delta Auth. Indep. Sci. Bd. Members (Feb. 22-23, 2005), available at http://science.calwater.ca.gov/pdf/isb/ISB_FEB-MTG_Key_Outcomes_Memo_and_Summary_ Final_DRAFT.pdf. 
highly critical of the lack of a coordinated research agenda. ${ }^{224}$ Reacting to that report, the Fish and Wildlife Service created a dedicated Desert Tortoise Recovery Office and empanelled an advisory committee of outside experts. The goals of the new office, in consultation with the advisory committee, included prioritizing and coordinating research activities, as well as evaluating the resulting data. ${ }^{225}$

Priority setting is one of the points at which engaging outside experts can be most valuable. There has been considerable discussion in recent years of the role of peer review in administrative decision making, with much of that discussion centered on individual environmental and natural resource decisions. ${ }^{226}$ Under the authority of the Information Quality Act, the Office of Management and Budget has directed all federal agencies to have important scientific information peer reviewed before disseminating it. ${ }^{227}$ As Dan Tarlock and I have explained elsewhere, peer review of individual management decisions by individual reviewers employing a journal-style model is unlikely to provide much additional constraint on agency judgments already bounded by professional norms and the threat of judicial review. ${ }^{228}$ Review of entire management programs by a standing committee, an ad hoc committee with the visibility of the National Research Council, or a less high-profile committee with the ability to publicize its views is a very different matter. On an ex post basis, that kind of review can significantly increase the transparency of agency judgments by forcing public explanation of the rationale behind those judgments. It can also spur learning, in part by bringing the latest research developments to the attention of agency scientists too busy to closely follow the evolving literature. But review is likely to be most useful in proactively helping to set research agendas, both because that can help avoid costly mistakes before they are made and because agencies are less likely to react defensively to input targeted to helping them make better future decisions than to criticism of past actions.

It can be difficult to recruit top scientists to serve on these sorts of review committees, which are time consuming and can embroil the participants in unwanted controversy. Some will volunteer out of a sense of obligation to make socially valuable use of their training, or because they care deeply about the success of the programs in question. Paying them for their time can help, as can the prestige of the sponsoring institution. Many scientists look at an invitation to serve on an NRC committee as a sign of professional validation, and their universities are likely to share that view. That may be a good reason for maximizing the NRC's role in program review. Reviewers could be encouraged to adapt their reviews for publication in the scientific literature, and prestigious journals could commit to creating suitable fora for these sorts of papers. Other sorts of rewards could be envisioned, such as prizes from professional societies for distinguished public service.

224. See U.S. GEN. ACCOUNTING OFFICE, supra note 210.

225. Desert Tortoise Recovery Office, http://www.fws.gov/nevada/desert_tortoise.

226. See J.B. Ruhl, Prescribing the Right Dose of Peer Review for the Endangered Species $A c t, 83$ NEB. L. REV. 398 (2004) (providing thoughtful discussion of the appropriate role of peer review in natural resource management); NAT'L RESEARCH COUNCIL, REVIEW PROCEDURES FOR Water Resources Project PlanNing (2002).

227. Final Information Quality Bulletin for Peer Review, 70 Fed. Reg. 2664 (Jan. 14, 2005).

228. Doremus \& Tarlock, supra note 123 , at 32. 


\section{Encourage Management-Relevant Exploration}

Many natural resource conflicts are plagued by limited knowledge of the basic functioning of the systems being managed. In part, this is certainly due to the difficulties of studying these systems and of sorting out the complexities of their processes. But there is more to it than that. There seems to be a systematic disconnect between the worlds of the exploratory researcher and of the natural resource manager. This cultural gap, which leads to information gaps, can be narrowed from both sides.

On the research side, we need stronger incentives for untethered, creative exploratory work on natural systems. One piece of that should be greater funding for ecological and environmental science, primarily in university settings. In fiscal year 2003 , the federal government devoted just over $\$ 200$ million to grants supporting university-based research in "environmental biology." 229 Given the billions of dollars and irreplaceable noneconomic interests at stake in resource conflicts, that investment should be substantially increased.

But simply throwing money at academic researchers will not guarantee success, especially if the researchers themselves are put in charge of distribution. Funding is only one factor in determining the questions researchers choose to tackle. Training and professional acculturation are also important. Scientists pursue questions their training equips them to perceive and answer. The quest for career advancement and prestige drives them toward the techniques and problems with the highest perceived status. In ecology and related fields, those are not the questions of most interest to managers. Academics have focused on producing complex mathematical models rather than on generating the basic life history information needed to drive those models. Paul Dayton sees a stark and depressing mismatch in priorities: "academics have fiddled while the natural world they argue about has burned." ${ }^{230}$ Dayton explains that natural history and taxonomy are essential to understanding the declines of species and ecosystems, but charges that "scientific elitism" has eroded the importance of those fields to the point that the foundation needed to address conservation problems is missing. ${ }^{231}$ As part of the broad priority-setting exercise advocated above, new investments in environmental research should target fields important to management efforts but underrepresented among new graduates. That can be done through targeted graduate and post-doctoral fellowships, as long as enough qualified mentors are available. It is important to revive the "ologies" before the last generation of practitioners disappears from university halls, lest we face the need to entirely reinvent these fields. ${ }^{232}$

229. See supra text accompanying note 51.

230. Paul K. Dayton, The Importance of the Natural Sciences to Conservation, 162 Ам. NATURALIST 1, 2 (2003); see also Paul K. Dayton \& Enric Sala, Natural History: The Sense of Wonder, Creativity, and Progress in Ecology, 65 (Supp. 2) SCIENTIA MARINA 199 (2001) (decrying the "demise of natural history," which the authors view as the essential foundation for creativity in ecological research).

231. Dayton, supra note 230, at 10-11. Vicky Meretsky echoed those concerns at this conference, pointing to a shortage of people learning the "ologies," the basic natural-historyoriented biology fields. Teresa Woods pointed out one consequence of that shortfall, that analytical tools outpace collection of data to analyze.

232. Dayton suggests that an entire generation of biologists has already grown up without the necessary background in natural history, so that some bootstrapping may already be needed 
It is also important to emphasize at the level of graduate training, where much professional acculturation occurs, the value of problem solving and of real-world engagement. This is one place where there is cause for optimism. Although academic incentives are often described as strongly resistant to change, in fact academic fads come and go with surprising rapidity. The demand for graduate training in particular sub-fields, and the capacity to provide that training, can respond quickly to changes in the employment market. Investment in a few dozen faculty positions at major research universities tied to contributions to the resolution of real-life resource management problems would go a long way toward encouraging students to pursue that type of science. In fact, it looks to me like students going into conservation-oriented fields these days do not need much prodding in that direction; all they need are opportunities and the endorsement of their mentors or key players in the field. At my own university, the ecology graduate students are already pushing the faculty toward giving more respect to problem solving rather than just high theory, and demanding that their education include, or at least provide room for, experience with policy-relevant issues. At the same time, university administrators faced with tight budgets and dwindling public funding commitments are paying more than lip service to the notion that higher education must prove its value to society by bringing knowledge to bear on the most pressing societal problems. ${ }^{233}$ University scientists who went into conservation-related fields because they care about the natural world have founded new disciplines, launched new journals, and created new professional societies to help bring academic prestige to problem-oriented work. ${ }^{234}$ Although they still provide only a small proportion of total research funding, nonprofit, problem-oriented funding sources increasingly allow practitioners of management-relevant research to support their work while meeting traditional measures of academic professional success. ${ }^{235}$ Even the most prestigious general-interest scientific journals have begun to respond, publishing highquality problem-oriented work, thereby giving that work instant academic respectability. Studies that are "surprising" from a management perspective are more likely than work confirming management assumptions to result in high-profile publications, providing research scientists with an added incentive to probe those assumptions. ${ }^{236}$

to revive these fields. $I d$. at $11-12$.

233. In a 1998 convocation address, for example, the Chancellor of UC Davis emphasized "the fully engaged university - the university's continuing obligation to full engagement in addressing societal problems." Larry Vanderhoef, Chancellor, UC Davis, Convocation Speech at UC Davis, http://chancellor.ucdavis.edu/Resource/commun/1998/convoc98.cfm. Since then, "the fully engaged university" has been a watchword throughout the UC system.

234. The most obvious example is the field of conservation biology, which was launched as an explicitly "mission-oriented" field and now has a professional society and several dedicated peer-reviewed journals.

235. Examples include the Packard Foundation, Resources Legacy Fund, Evan Frankel Foundation, and Switzer Foundation, among others.

236. As just one example, the Independent Scientific Group on Cattle TB convened by Great Britain's Department for Environment, Food, and Rural Affairs published two papers on studies demonstrating that badger culling can actually increase bovine TB. Donnelly et al., supra note 67, at 843; Donnelly et al., supra note 64 , at 834 . Closer to home, the National Center for Ecological Analysis and Synthesis (NCEAS) in Santa Barbara has supported several workshops closely tied to resource management problems that have produced peer-reviewed publications. For example, one produced a major study of recovery plans under the ESA that became a 
Help in closing this gap can also come from the agency side. Management agencies should not directly control decisions about what exploratory work is done, because it is too likely that those decisions would be strongly skewed by agency culture and mission. ${ }^{237}$ But agencies do need to build stronger links with free-wheeling research scientists and the academic research culture, which is far more tolerant of mistakes (which can often be "productive" in the sense of advancing knowledge) and strong directional shifts, and at the same time far more demanding that scientists constantly defend their intuitions, interpretations, and research choices. Researchers also need stronger links to management institutions to help keep them aware of the kinds of challenges managers face and the information they might be able to use. These links can be encouraged by, for example, making student fellowships available for work linked directly or indirectly to management decisions, by offering funding for students to work with agency personnel or for agency personnel to spend "sabbaticals" at research institutions, ${ }^{238}$ or even just by creating nonthreatening opportunities for researchers and managers with common interests to meet and exchange experiences, concerns, and frustrations.

Management agencies can also act to lower bureaucratic hurdles, which can pose significant practical barriers to independent research. Research scientists are not known for their patience with bureaucratic procedures and paperwork, especially if those things create delays, require approval by functionaries who do not (from the researcher's perspective) fully understand the project, and (again, to the researcher's eye) serve no useful function. I am told, for example, that controlled experiments testing the impact of forest fires on water quality could be, but are not, being done on national forest lands in part because of the frustrations potential researchers have experienced with the NEPA compliance process. ${ }^{239}$

With a little creative thinking, agencies can ease these sorts of burdens without threatening the resources for which they are ultimately responsible. Agencies could, for example, assign staffers who are familiar with NEPA and ESA processes to

special issue of the journal Ecological Applications. Peter M. Kareiva, Applying Ecological Science to Recovery Planning, 12 ECOLOGICAL APPLICATIONS 629 (2002) (introduction to the special issue). On its web site, NCEAS claims to have produced over 1000 publications, many in leading journals. Evidence of the Impact of NCEAS, http://www.nceas.ucsb.edu/statistics.

237. For evidence of that kind of skewing, one need look no further than the history of Forest Service research stations. See Rigg, supra note 6, at 86 ("In past decades, USFS research focused on the growth rate, yield, and genetic resistance of individual species, reflecting an organizational culture based on traditional resource management values.").

238. The University of California and the California Resources Agency launched an innovative fellowship program in 1995 designed to bring agency personnel into the university for a year or less and vice versa. University of California-Davis, Public Service Research Program, State and Regional Agency Partnerships and Collaborations, http://psrp.ucdavis.edu/. It has proven easier to attract agency personnel to academia than the other way around, but providing additional rewards for academic problem solving, and offering roles in the thick of interesting problems, could potentially correct that imbalance.

239. After spending a year working with the staff at one national forest to set up a controlled study of the impacts of fire on forest ecosystems and faced with the possibility that an environmental assessment could take another two years or more, one UC Berkeley professor moved his study to a University of California research forest, where exhaustive environmental analysis was not required. E-mail from Scott Stephens, Assistant Professor of Fire Science, UC Berkeley (Aug. 15, 2006) (on file Indiana Law Journal). 
shepherd high-priority research proposals through the bureaucratic maze. Ramping up the level of resource commitment a bit, management agencies could designate specific geographic areas for wide-ranging exploratory studies. They could carry out any required environmental assessments at the time of designation, or on a "worst case" basis if it is not possible to predict what sorts of studies might be carried out, rather than waiting until they receive research proposals.

A somewhat more systematic version of the Forest Service's existing network of experimental forests could greatly enhance the opportunity for resource management experimentation. Designation of experimental forests began in 1908; today there are 77 experimental forests scattered around the country, including the famous Hubbard Brook National Forest, site of the experiments that first convincingly revealed the effects of acid precipitation. ${ }^{240}$ Although the system has grown in a fairly ad hoc manner, it contains representatives of twenty-one of the twenty-five forest cover types in the United States and covers a broad range of environmental conditions. ${ }^{241}$ Many units host long-term studies with important management implications. ${ }^{242}$ Work at the experimental forests is not, however, well networked, nor have the individual sites been selected for importance to current and future management issues.

Should a priority-setting exercise be undertaken as recommended above, ${ }^{243}$ one of its tasks could be to identify other sites that might be added to the experimental forest system. Another could be to outline a strategic research plan integrated across the sites. An integrated research network could reduce bureaucratic barriers by, among other things, giving managers the confidence to sanction risky but potentially promising management experiments. Experimental locations should be chosen for their potential value to management decisions, but that does not mean they must necessarily be in the core habitat of protected species, where experiments might present greatest conservation concern. For species with a wide range, secure protection in one location might allow another location to be used freely for controlled experimentation, even if that means possible extirpation from parts of the experimental area. At least some types of experiments can be monitored, and treatments that show a strong adverse effect on resources of concern can be terminated early, as they are in human drug trials. ${ }^{244}$ Furthermore, if researchers are thinking creatively, they may be able to reason

240. Ariel E. Lugo, Frederick J. Swanson, Olga Ramos Gonzalez, Mary Beth Adams, Brian Palik, Ronald E. Thill, Dale G. Brockway, Christel Kern, Richard Woodsmith \& Robert Musselman, Long Term Research at the USDA Forest Service's Experimental Forests and Ranges, 56 BIOSCIENCE 39 (2006).

241. Id. at 43-44.

242. Id. at $45-46$.

243. See supra Part II.B.

244. See Fischman \& Meretsky, supra note 6, at 94 (noting that experiments might have to be ended early if they might jeopardize a listed species). There is apparently no clear formula for when drug trials must be halted due to adverse effects, but certainly if patients die unexpectedly or of unexpected causes a red flag is raised for researchers. See Matthew C. Lovell, Second Thoughts: Do the FDA's Responses to a Fatal Drug Trial and the AIDS Activist Community's Doubts About Early Access to Drugs Hint at a Shift in Basic FDA Policy?, 51 FOOD \& DRUG L. J. 273 (1996) (explaining the drug trial process and recounting an instance of fatal liver complications during trial of a hepatitis drug). Naturally, there is always room for argument about the degree of acceptable risk in a research trial, as well as about the extent to which potential negative consequences should be foreseen or detected early. 
by analogy, extrapolating from observed effects on suitable but unoccupied habitat, or on similar but not endangered species.

Finally, learning could become a performance measure for managers. Too often, performance in management agencies is measured simply by "bean counting," keeping track of the number of management actions or the amount of money spent on management. That sends precisely the wrong message to managers, encouraging them to act without either reflection before the fact or evaluation after. Evaluating managers on the extent to which they produce new knowledge about the system would provide career incentives for learning. Measuring learning, however, is a tricky proposition. ${ }^{245}$ It will not always be reflected in measurable improvement in the resource in the short run; indeed, tying performance evaluations too closely to resource status can discourage experimental approaches. Management learning might be usefully evaluated through the kinds of performance screens applied in academic science-by publication in the peer-reviewed literature, or if that seems too slow and laborintensive, by outside scientific review of written or oral explanations of what is known about the system and how gaps are being addressed. ${ }^{246}$ Even simply setting into place periodic exercises in active reflection and evaluation by, for example, requiring regular written reports on how the knowledge base has (or has not) changed can facilitate learning. ${ }^{247}$

\section{Make Sure Extraction Keeps Pace}

No matter how productive exploration is, if the data it makes available are not extracted it can never play a role in management decisions. It's not surprising, given the ease of cataloging extraction shortfalls, ${ }^{248}$ that scientists and managers alike express frustration at the failure of fundamental data production to keep up with theoretical advances. In 1994, Mark Shaffer and colleagues complained that, twenty years after population viability analysis was developed, lots of sophisticated computer modeling had been done, but the models were of limited usefulness because little of the field data needed to ground-truth and drive them had been produced. ${ }^{249}$ The situation does not seem to have improved much in the intervening decade. Resource

245. Stankey et al., supra note 56 , at 46 cite the need to make learning a management "performance element" in order to encourage adaptive management, but do not elaborate on how that might be done.

246. The Cal-Fed Bay Delta science program in its first iteration emphasized peer review by standing advisory committees, which seems well-suited to this kind of function. It is difficult, however, to persuade reviewers to commit the kind of time and effort needed for an engaged, long-term review process. Where the management effort is sufficiently important or high profile, that alone may have considerable motivating power. Cal-Fed provided generous consulting payments to its outside reviewers, which may not only encourage agreement to participate but "guilt" committee members into robust engagement. Encouraging reviewers to get involved in ways that facilitate publication and joint thinking beyond the narrow specifics of the management measures evaluated might provide additional intellectual incentives.

247. Ioan Fazey, John A. Fazey \& Della M. A. Fazey, Learning More Effectively from Experience, 10(2) ECOLOGY \& SOC'Y 4 (2005) available at http://www.ecologyandsociety.org/ vol10/iss $2 /$ art 4 .

248. For a very partial list, see supra text accompanying notes 95 to 105 .

249. Shaffer et al., supra note 5, at 130. 
managers participating in this conference noted that they have plenty of data analysis tools, but not enough data to analyze. ${ }^{250}$

As explained above, there may be reason for optimism that evolving academic incentives will help address this shortfall. ${ }^{251}$ Nonetheless, more directly targeted steps should be taken to address the extraction shortfall. Leadership from the political and nongovernmental arenas will be essential.

Targeted funding, free from annual appropriations struggles, ought to be provided both for general indicator tracking and for specific high-priority extraction efforts. Investment in development and regular monitoring of a broad range of indicators may produce some short-term results relevant to specific management situations, but its greater value is likely to be in inspiring novel exploratory studies and highlighting impending resource conflicts over the longer term.

The government should finance much of the big-picture monitoring and extraction, as well as the lion's share of exploration. It is common for government to subsidize the research and development costs of private industry when the research is costly and carries a high risk of failure and the industry is seen as important to societal interests. ${ }^{252}$ The case for subsidizing the supply of information to natural resource managers is even stronger. Private actors will not voluntarily assume the costs of information supply to a process that ultimately is more likely to limit than to enhance profits. It can be argued that extractive interests should internalize the costs of assuring that their actions are consistent with societal conservation goals, but exploratory research and generalized environmental monitoring efforts typically do not enable any particular extractive activities. ${ }^{253}$ Later in the process, when identified private resource users are involved, it will generally be appropriate for those users to share in the costs of information production, although it may still be desirable for government or university scientists to actually do the work.

250. See also Jordan S. Rosenfeld \& Todd Hatfield, Information Needs for Assessing Critical Habitat of Freshwater Fish, 63 CANADIAN J. FISHERIES \& AQUATIC SCI. 683, 686 (2006) ("sufficient information to perform a PVA is often lacking for listed species, usually because time and resources have not been available to obtain the necessary demographic parameters").

251. See supra text accompanying notes 232 to 236 .

252. The oil industry, of course, has benefited from a range of government subsidies since its inception. See Mona Hymel, The United States' Experience with Energy-Based Tax Incentives: The Evidence Supporting Tax Incentives for Renewable Energy, 38 LoY. U. CHI. L.J. 43, 46-53 (2006) (documenting range of tax incentives offered to the oil industry); Roberta F. Mann, On the Road Again: How Tax Policy Drives Transportation Choice, 24 VA. TAX Rev. 587, 651-653 (2005) (noting ongoing tax subsidies in various forms). More generally, since 1981 a federal tax credit has been in place for a portion of the research expenses of any business. 26 U.S.C. $\$ 41$. The total subsidy from the research tax credit was reportedly more than $\$ 24$ billion by 1994 , with over $\$ 4$ billion of that going to the pharmaceutical industry alone. NATIONAL SCIENCE BOARD, SCIENCE AND ENGINEERING INDICATORS-1996, at 4-20 to 4-21 (1996).

253. Professor John Applegate argues that government, rather than industry, should play the primary role in filling data gaps "when there is structural or systematic market failure, when government is in a position to generate the information, and when industry's credibility gap is particularly acute." Applegate, supra note 3, at 269. All of these factors point toward government funding in the typical natural resource management context. 
While government funding is appropriate it is also, as the discussion above demonstrated, ${ }^{254}$ extraordinarily difficult to obtain. Strong political leadership might help, but even that will not be enough if it comes from only one side of the aisle, as Bruce Babbitt learned when he created the National Biological Survey. Bipartisan agreements on the value of information, however, can shake loose funding, at least temporarily. The dedication of a substantial portion of Cal-Fed's initial funding to a highly independent science program is one hopeful example.

If the government cannot or will not fund extraction, the conservation community can, and to some extent already does, help take up the slack. Scientists throughout the world provide data on the status of species to the International Union for the Conservation of Nature and Natural Resources (IUCN), which periodically compiles those data to produce its Red List, the standard resource on global biodiversity threats. ${ }^{255}$ The use of nonspecialist volunteers to perform certain types of data gathering can also reduce the costs of extraction, while producing information that is both useful and reliable. In the United States, for example, National Audubon Society chapters across the country coordinate a Christmas Bird Count. Begun in 1900 by twenty-seven birders in twenty-five locations, mostly in New England and the midAtlantic, the Christmas Bird Count has grown to encompass nearly 2000 sites and more than 50000 participants. With no cost for the data collection itself, the Count provides valuable information about changes in the distribution of North American bird populations over time and space. ${ }^{256}$ More recently, Audubon has initiated other "citizen science" programs, including a nationwide backyard bird count and a web site that allows birders to contribute other sightings to an online database. ${ }^{257}$

Government efforts would be enhanced by the creation of an agency or office whose mission explicitly included prioritizing, carrying out, and overseeing information extraction. That institution should be instructed to take a big-picture view, prioritizing extraction needs, and to commit to target dates for implementing specified measures. ${ }^{258}$ The National Biological Survey (NBS) might have served this purpose, but of course it was derailed by political opposition. Today, the USGS, or its Biological Resources Division, are the most obvious candidates for this role. It is unlikely that the political landscape has changed so much since the NBS debacle that it would be easy to get Congress to endorse the concept of a natural resources information agency, especially one explicitly serving management needs. But perhaps it could be more effectively sold by pointing out that better information can sometimes

255. See supra text accompanying notes 94-112.

256. IUCN, Species Survival Commission, 2006 IUCN REd LisT OF THREATENED SPECIES, available at http://www.iucnredlist.org/.

257. National Audubon Society, Christmas Bird Count, History and Objectives, http://www.audubon.org/bird/cbc/history.html.

258. National Audubon Society, Citizen Science, http://www.audubon.org/bird/citizen/ index.html.

259. The USGS BRD strategic plan includes an impressive list of data extraction efforts, but it does not show evidence of big-picture evaluation, nor does it include target dates. Paul V. Dresler, Daniel L. James, Paul H. Geissler, Timothy M. Bartish \& James Coyle, Strategic Plan for the U.S. Geological Survey Status and Trends of Biological Resources Program: 2004-2009, Circular 1277 (2004), http://biology.usgs.gov/status_trends/Ststrategicplan.pdf. It is impossible to determine from the agency's web site to what extent the plan has been implemented. 
release, rather than add, management inhibitions. In any case, it can't hurt to publicly point out the inconsistency of demanding "sound science" for resource management while at the same time refusing to invest in that science.

Finally, although many others have said it before, it bears repeating: in order to create incentives that favor information extraction we must avoid rewarding ignorance. ${ }^{259}$ To the extent that information extraction requires access to private lands, it is essential that landowners who fail to provide access find it more difficult, rather than easier, to develop. ${ }^{260}$ Even when government agencies have full access to the resource, political pressures are likely to inhibit extraction if lack of knowledge means economic activity can proceed unhindered.

\section{E. Break Down Disciplinary and Institutional Barriers}

One of the biggest barriers to both the production and the use of information is the landscape of isolated disciplinary and institutional silos confining researchers and managers.

On the research side, those trained in established disciplines tend to see management problems through their peculiar disciplinary lenses and to push as universal solutions whatever maximizes the importance of their discipline. ${ }^{261}$ As with exploration and extraction, there are some hopeful signs of change in academia with respect to the importance of disciplinary boxes. Universities are increasingly acknowledging the importance of interdisciplinary approaches, especially to environmental problems, and establishing interdisciplinary centers and programs. ${ }^{262}$ Government funding institutions are rewarding, or even requiring, grant proposals encompassing multiple participants from diverse disciplines. ${ }^{263}$

Still, much more remains to be done. Many observers consider the current emphasis on multidisciplinary training and research in universities and funding agencies to be superficial. It is widely believed that academic incentives still favor disciplinary depth

260. See Wagner, supra note 18.

261. Polasky \& Doremus, supra note 90.

261. See supra text accompanying notes $120-21$.

262. Recently established multi-disciplinary academic institutions include the Nicholas School of the Environment and Earth Sciences at Duke University and the Donald Bren School of Environmental Science and Management at the University of California, Santa Barbara.

263. One example is the National Science Foundation's Integrative Graduate Education Research and Training grant program which, according to NSF "has been developed to meet the challenges of educating U.S. Ph.D. scientists and engineers . . . with the interdisciplinary backgrounds, deep knowledge in chosen disciplines, and technical, professional, and personal skills to become, in their own careers, leaders and creative agents for change. The program is intended to catalyze a cultural change in graduate education, for students, faculty, and institutions, by establishing innovative new models for graduate education and training in a fertile environment for collaborative research that transcends traditional disciplinary boundaries. It is also intended to facilitate diversity in student participation and preparation, and to contribute to the development of a diverse, globally-engaged, science and engineering workforce." National Science Foundation, Integrative Graduate Education and Research Traineeship Program (IGERT), http://www.nsf.gov/funding/pgm_summ.jsp?pims_id' 12759\&from'fund. 
over interdisciplinary breadth. ${ }^{264}$ Those two, of course, need not be in tension. Excellent disciplinarians could be encouraged to work with similarly excellent practitioners of other disciplines, rather than being told that they alone must master all the disciplines relevant to the environmental problems that most interest them. This process must begin at the graduate student level, if not before. Simply exposing students to the perspectives, importance, and complexities introduced by other disciplines can go a long way toward breaking them free of their silos. ${ }^{265}$ Not all graduate students should be expected to do interdisciplinary work; there is still considerable value to be gained, on an academic and management level, from studies within a single discipline. But no challenging modern environmental problem is strictly within the realm of any one discipline, so none can be solved without some researchers breaking the disciplinary mold.

Faculty too can be encouraged to break out of these silos. Perhaps the best incentive for doing so is the realization that their colleagues in other disciplines can provide a new perspective on problems they have seen as intractable, or can highlight the importance of complications they had not understood. The first step might be informal interaction-once faculty from disparate disciplines know and trust one another, they can explore overlapping research interests ${ }^{266}$ and begin to break through the jargon that separates them. ${ }^{267}$ The next might be institutional incentives to attempt the first collaboration.

On the management side, the analogous need is for personnel willing and able to transcend institutional boundaries. Resource conflicts almost by definition are not readily confined either by political or by institutional limits. In order to pursue a bigpicture approach, not only to management itself but also to the information demands of management, institutions must break free of their geographic, media-specific, and mission-oriented boundaries. There are some hopeful signs in the recent creation of

264. See, e.g., Bammer, supra note 132, at 6 .

265. A group at UC Davis funded by the National Science Foundation has had great success exposing graduate students in ecology, population biology, history, economics, and other disciplines to the multi-disciplinary perspectives required to get an intellectual grasp on the problem of biological invasions. For a description of the program, see http://www.cpb.ucdavis.edu/bioinv/.

266. See, e.g., Degnbol et al., supra note 69 , at 542 ("Before cross-disciplinary interaction works on an informal basis, we cannot assume that it will work on a formal basis. Colleagues need to know each other well and respect each other before they can be expected to be creative together and to take on shared responsibilities, for instance a joint research grant."). My own experience suggests this statement may be a bit too strong, but it has more than a grain of truth. Where a funding call demands multi-disciplinary participation, one researcher or disciplinary group may take the initiative, and later call on another discipline to endorse what is already almost a fully-fleshed out project. Quite often that serial disciplinary approach produces resentment, but sometimes it may be an effective ice-breaker. It's unlikely to produce top-flight cross-disciplinary research the first time out, but it may lead to the kinds of mutually respectful interpersonal relationships, and the familiarity with one another's research interests, that are the foundation of the best cross-disciplinary research.

267. See Katharine Jacobs, Gregg Garfin \& Melanie Lenart, More Than Just Talk: Connecting Science and Decisionmaking, 47(9) ENV'T, Nov. 2005, at 6, 13 ('Use of jargon may be one of the most significant limitations to applied interdisciplinary work and integrating science with decision making."). 
novel eco-regional institutions, such as the Cal-Fed Bay-Delta program, the Comprehensive Everglades Restoration Plan, and the Platte River Collaborative Watershed Planning Process. ${ }^{268}$ Clearly, though, much work remains to be done. Although all of these programs cross political jurisdictions and bring together multiple mission-oriented agencies, none of them is fully integrated across the environmental spectrum. All concentrate on the distribution and quality of geographically discrete water resources, focusing on a relatively small universe of big users or major pollution sources. Furthermore, none has yet demonstrated staying power in the face of tough budget climates. The Cal-Fed experience sounds a particularly cautionary note. The Cal-Fed program in its original, cooperative federal-state form, is essentially dead. Attempts are ongoing to revive it as a strictly state institution, but whether that will work at all, and if so whether it will prove adequate to the scope of the challenges, remains to be seen.

\section{F. Archive Information in Accessible Places and Useable Forms}

Too often, resource managers find themselves reinventing the wheel or unable to evaluate the success of similar management actions because information that has been gathered is not made available, or is not available in a standardized format. Given modern information management and distribution tools, relatively small investments ought to be able to make a big dent in that problem.

There are conspicuous examples of failures to take the seemingly simple step of making information extracted for one purpose at one time by one source available for others for subsequent use or reevaluation, ${ }^{269}$ but there are also some successful examples to draw on. One is FishBase ${ }^{270}$, a publicly accessible, free internet database compiling primarily biological but also some other information about nearly thirty thousand fish species. ${ }^{271}$ FishBase is heavily used, receiving about 20 million hits per month from users worldwide. ${ }^{272}$ Its usefulness to fisheries researchers is attested to by the long and rapidly growing list of scientific papers that cite to it as a data source. ${ }^{273}$

268. See Joseph L. Sax, The New Age of Environmental Restoration, 41 WASHBURN L.J. 1 (2001) (describing all three). Dan Farber and Jody Freeman propose the need for "modular" institutions, characterized by flexible coordination between government agencies, and with private entities. They describe the Cal-Fed program as an example of modularity. Freeman \& Farber, supra note 219 at 795.

269. See supra text accompanying notes $146-48$.

270. http://www.fishbase.org.

271. Cornelia E. Nauen, Implementing the WSSD Decision of Restoring Marine Ecosystems by 2015-Scientific Information Support in the Public Domain, 30 MARINE POL'Y 455, 457 (2006).

272. Id. at 456.

273. By early 2006 , FishBase reportedly listed some 1125 publications citing it, with most of those dated after it became available on the internet (instead of solely on CD) in 1999. Id. at 458. By July 2006 , the number had grown only slightly, to 1169 , suggesting perhaps that some of those citations were for novelty alone. Not all of those citations appear in traditional papers. Many are in web sites. Perhaps FishBase is most useful as a communication mechanism available to share with wide audiences. 
FishBase also reaches out to take advantage of its user community's expertise, allowing easy submission of comments, links, and suggestions. ${ }^{274}$

In order for scientific information to be usable by interested stakeholders as well as by specialists, it must be expressed in accessible formats. Here, the fisheries world provides another positive example. The Sea Around Us Project has a web site ${ }^{275}$ intended to make information about fisheries status available to the public. It displays graphically, and in eye-catching spatial displays, information that might otherwise lie buried in obscure scientific publications. ${ }^{276}$

\section{CONCLUSION}

Management of natural resources subject to conflicting demands is a challenging business for any number of reasons, but certainly the dearth of available information about the consequences of management choices is one of the most important. We should not underestimate the barriers to understanding the complex natural systems we are now in the business of managing, falling prey to what has been described as "a naively generous comprehension of how much ecologists and wildlife biologists know of the natural world, and the ease and rapidity with which that knowledge can be increased." ${ }^{277}$ Expecting too much of scientists leads to the "sound science" movement and unrealistic thresholds for changes to the status quo. That is hardly a recipe for effective conservation.

But it is just as wrong-headed, and potentially just as harmful to the conservation enterprise, to assume that data gaps are an irreducible natural phenomenon. Considerable uncertainty will always remain, but there are opportunities to make better use of existing information, to maximize extraction of information where feasible, and to more effectively explore for new information sources.

Taking advantage of those opportunities will require committed leadership from both sides of the research/management divide. That leadership must be attentive to shortcomings on its own side of the ledger, sensitive to challenges on the other, and dedicated to problem solving above personal advancement. Bridging the cultural gaps that interfere with effective data supply is necessarily a long-term process that will require adjusting training and professional expectations on both sides.

Reducing data gaps will also require commitment from political actors, who must make funding available, construct new management institutions with the ability to see and act across traditional boundaries, and establish a balance in those institutions between the flexibility needed for experimentation and the oversight necessary to demand evidence of learning. It will have to be an incremental process; the needed changes are systemic and cannot happen overnight. One good place to start would be with a broad overview of the types of exploratory research that might be of greatest value to management, and how research funding might help promote that research. Another is with the project of cataloging resource data as they are produced; making them accessible to managers, researchers, and the public; and making them useful,

274. Id. at 459 .

275. http://www.seaaroundus.org.

276. Nauen, supra note 272 , at 459.

277. Shaffer et al., supra note 5, at 129. 
through format uniformity and database searchability, across the broadest possible spectrum.

The first step toward a cure is always to admit that the patient has a problem. In the case of natural resource management, that means getting beyond the misleading and oppositional claims that, on the one hand, we need to act in the face of uncertainty and, on the other, we need enough information to know what we're doing. Once we admit that less-than-perfect information may be both useful and attainable, we can ask the key questions: what information we have, whether we are making full use of it, what additional information would be useful, and what it would take to obtain that added information. Perhaps when we are able to take a close look we may find that, while not full, the glass is less empty than either side has believed. 
HeinOnline -- 83 Ind. L.J. 4642008 